\title{
ARTÍCULOS
}

\section{LOS TRES JUICIOS A FELIPE SENTENACH. EL ROL POLÍTICO DE LA JUSTICIA EN BUENOS AIRES (1807-1812).}

David Martínez Llamas

Universidad de Barcelona dmllamas@gmail.com

Resumen: Utilizando como eje los juicios realizados a Felipe de Sentenach entre 1807 y 1812, en tres momentos clave de la historia rioplatense, analizaremos los cambios políticos, las fidelidades y las luchas entre los personajes que lideraron los procesos que llevaron a la Revolución de Mayo y a su dirección.

Palabras clave: Justicia, invasiones inglesas, Revolución de Mayo, milicianos, Río de la Plata.

Tittle: THE THREE TRIALS TO FELIPE DE SENTENACH. THE POLITICAL ROLE OF JUSTICE IN BUENOS AIRES (1807-1812).

Abstract: Using as an axis the judgments of Felipe de Sentenach between 1807 and 1812, in three key moments of the Rio de la Plata's history, we will analyze the political changes, the loyalties and struggles between the characters who lead the processes that led to the May Revolution and its leadership.

Keywords: Justice, British invasions, May Revolution, militiaman, Rio de la Plata.

\section{Introducción}

El presente trabajo analiza cómo las luchas por el poder, iniciadas en el Virreinato del Río de la Plata con las invasiones inglesas de 1806 y 1807, provocaron una paulatina división de la población en torno a dos grupos con planteamientos diferenciados. Estas oposiciones se alimentaron del convulso contexto sociopolítico, tanto americano como europeo, en el que se generaron y siguieron creciendo hasta el punto álgido del 25 de mayo de 1810, cuando se instala una Junta Gubernativa Provisional en Buenos Aires, y finalizando drásticamente en el agitado año de 1812.

Muchos de estos conflictos internos de la sociedad virreinal han sido reiteradamente invisibilizados por la historiografía, porque sobre ellos «triunfa el acontecimiento singular (...) que, por su carácter único, modifica de modo irreversible

Cómo citar este artículo: MARTÍNEZ LLAMAS, David. Los tres juicios a Felipe de Sentenach. El rol político de la justicia en Buenos Aires (1807-1812). Naveg@mérica. Revista electrónica editada por la Asociación Española de Americanistas [en línea]. 2019, n. 23. Disponible en: $<$ http://revistas.um.es/navegamerica>. [Consulta: Fecha de consulta]. ISSN 1989-211X. 
las situaciones políticas ${ }^{1}$, generando una mitología que se sobrepone al resto de procesos, incluyendo al mismo que lo ha provocado ${ }^{2}$. En nuestro caso, el «hecho singular» fueron tanto las invasiones inglesas como la instauración de la mencionada Junta, punto de inflexión del paso de una estructura virreinal a otra autónoma. $Y$ justamente es por su gran importancia que los silencios que las envuelven han generado en la memoria colectiva concepciones parciales y dualistas (buenos y malos) que han creado más incógnitas que explicaciones. Por ese motivo pretendemos poner el foco en algunos episodios específicos de estas luchas intestinas que, a nuestro parecer, lejos de ser simples anécdotas fueron claramente decisivos.

Para poder seguir la evolución de estas confrontaciones nos centraremos en los tres juicios que se realizaron contra la persona de Felipe de Sentenach, en tres momentos clave de la historia rioplatense. Queremos señalar ya desde el inicio, que el análisis de dichos procesos no se hará bajo un punto de vista legalista, sino bajo un prisma político con Sentenach como hilo conductor, revisando a quién interesaban y qué consecuencias tuvieron. La idea es servirnos de la biografía de este personaje no por ser excepcional o representativa sino por revelar los "diferentes sociales» ${ }^{3}$ de su entorno y por estar inmersa en las luchas internas de la sociedad porteña. De esta forma no solo conseguimos desvelar los conflictos, las oposiciones y las relaciones sociales que dieron lugar al propio litigio, sino que añadiremos una visión sobre qué cambios, si los hubo, se produjeron en la manera de impartir justicia y su relación con el poder.

La elección de Sentenach responde a la idoneidad del personaje que permite, a través de sus vivencias, analizar cómo evolucionó la participación popular en las luchas contra los ingleses, revisando el proceso de creación del cuerpo de los Patriotas de la Unión y las filiaciones generadas con él, así como entender el final de la resistencia interna a la Revolución rioplatense por parte de algunos peninsulares. Sus vinculaciones con personajes de alta relevancia social, política y económica como Martín de Álzaga, nos permite acercarnos a un segundo nivel de conflicto, el de las propias instituciones virreinales en un momento en que la sociedad está inmersa en una re-estructuración por el cambio de paradigma político. Queremos destacar que el personaje de Sentenach ha sido poco investigado hasta el momento tanto por la historiografía argentina como por la peninsular, siendo asociado a Martín de Álzaga y quedando olvidada y desdibujada su participación directa.

Para entender la importancia de la cronología de los mencionados juicios, seguidamente presentaremos cuándo se produjeron, en qué momento de quiebre o re-construcción se encontraba el territorio y cuál fue su significado a nivel político:

\footnotetext{
1 GUERRA, F.X. Modernidad e independencias. Ensayos sobre las revoluciones hispánicas. Madrid: Encuentro, 2009, p. 33.

2 BACZKO B. Los imaginarios sociales. Memorias y esperanzas colectivas. Buenos Aires: Nueva Visión, 1999, p. 12.

${ }^{3}$ REGUERA, A. De las biografías a los estudios de caso. La construcción de la diferenciación social. En: BONAUDO, Marta; REGUERA, Andrea y ZEBERIO, Blanca (coords.). Las escalas de la historia comparada. Tomo I: Dinámicas sociales, poderes políticos y sistemas jurídicos. Buenos Aires: Miño y Dávila Editores, 2008, p. 49.
} 
- 1807: Las invasiones inglesas - Ruptura de la estructura virreinal.

- 1809: Luchas internas - Acción/reacción: Asonada y Primera Junta.

- 1812: Construcción revolucionaria - Fin de la disidencia interna.

Para ilustrar mejor este contexto seguidamente mostraremos cómo esas luchas iniciadas en 1806 respondían a tres niveles de conflictividad. En primer lugar a la conflictividad imperial de una metrópolis inmersa en las guerras napoleónicas, que no sólo sufrió las consecuencias propias del uso de las armas sino también aquellas derivadas de los conflictos políticos provocados por el vacío de poder y de las alianzas (des)hechas. En segundo lugar, a una lucha de las élites locales de la sociedad rioplatense que, poco a poco, se aglutinaron alrededor de dos corporaciones - líderes. Estos conflictos estuvieron influenciados tanto por los cambios en la mentalidad política del momento, como por el quiebre del paradigma social virreinal con la aparición de la participación política popular y los intereses de la población criolla. Por último, pero no menos importante, serán las consecuencias de las ambiciones personales que servirán de combustible para este explosivo contexto. No sólo veremos las conocidas oposiciones y ambiciones de Martín de Álzaga y Santiago de Liniers sino también, y más importantes en este análisis, las de Felipe de Sentenach y Gerardo Esteve y Llach.

Esta gran conflictividad fue la predominante en los cuatro años que llevaron de una sociedad estructurada con un formato virreinal a un proceso revolucionario que sirvió de andamio para la reestructuración de todo un continente. Para poder analizar realmente qué significaron estas tres causas, nos es necesario vincularlos continuamente con el contexto del que partieron, ya que estos litigios:

«...no sólo eran instrumentos para criminalizar a quienes exhibían disidencias o eran considerados opositores, sino que también expresaban las percepciones de los actores en torno a la lógica de competencia por el poder, (...) puede dar cuenta de las disputas originadas en la precaria situación que el Río de la Plata atravesaba como resultado de la crisis de la Monarquía española. En esas circunstancias se agravaron sospechas y temores ya instalados en el territorio rioplatense con las invasiones inglesas y el cuestionamiento de la autoridad virreinal que le siguió» ${ }^{4}$.

En cuanto a las fuentes utilizadas en este estudio, diferentes instituciones argentinas, en un proceso de re-creación de una memoria colectiva nacional, han editado íntegramente documentos relacionados con el proceso de independencia, que han servido de base en nuestro estudio. En ellos se incluyen textos sobre las invasiones inglesas (ruptura de la estructura virreinal) así como los expedientes judiciales, con su documentación adicional, de las causas de $1809^{5}$ y $1812^{6}$.

\footnotetext{
${ }^{4}$ POLASTRELLI, I. Faltando a los deberes de buen vasallo. El juicio a los acusados de intentar independizar el Río de la Plata, 1809-1810. En: POLIMENE, María Paula (coord). Autoridades y prácticas judiciales en el Antiguo Régimen. Problemas jurisdiccionales en el Río de la Plata, Córdoba, Tucumán, Cuyo y Chile. Rosario: Prohistoria ediciones, 2011, p. 203.

${ }^{5}$ Biblioteca de Mayo. T.XI: Sumarios y expedientes: Documentos relativos a los sucesos ocurridos en Buenos Aires el 1ํ de enero de 1809. Buenos Aires: Senado de la Nación, 1961 y Biblioteca de Mayo. T.XII. Sumarios y expedientes: Proceso contra Martin de Álzaga, Felipe de Sentenach y José Miguel de Ezquiaga. Buenos Aires: Senado de la Nación, 1961.
} 
También las nuevas aportaciones de la historiografía sobre la re-visión de «lo político ${ }^{7}$ en donde el análisis de la justicia ha devenido central y nos han servido para encarar nuestro estudio desde una nueva óptica.

En los últimos años, los nuevos investigadores interdisciplinares que se han aproximado a la justicia, lo han hecho con la intención de no entenderla únicamente en su vertiente legal, sino dándole protagonismo al entorno político en el que se produjo y a los grupos que la implementaron. Tal es el caso de Magdalena Candioti, que en su tesis doctoral nos da una acertada definición de qué fue la justicia para la política durante estos años:

«Se trata de un espacio de intersección entre la voluntad de control y regulación social de las élites y su (in)capacidad de encausar las prácticas sociales; un área cuyos rasgos y cuyas relaciones con otras funciones políticas son una cuestión central a definir en los procesos de construcción estatal»».

Con esta base analítica nos aproximaremos a las fuentes judiciales, sin descartar aquellas obras anteriores con una aproximación documental más tradicional, consiguiendo de esta forma una visión más panorámica de los procesos. A los estudios publicados añadiremos las informaciones encontradas en los documentos originales del Archivo General de la Nación de Buenos Aires (AGN) y el Archivo General de Indias (AGI) sobre Sentenach y las invasiones inglesas, que nos permitirán enriquecer nuestro aporte.

Un problema bibliográfico con el que nos hemos encontrado ha sido la centralidad de la figura de Martín de Álzaga en los análisis de las obras que se aproximan a los juicios de 1809 y 1812. En numerosas publicaciones, se muestra cierta carga negativa sobre este y otros personajes por su posicionamiento político contrario a la Junta del 25 de mayo de 1810 (inicio para muchos de la historia nacional rioplatense) y a los grupos que la lideraron. Aunque actualmente se han iniciado análisis que revisitan a estos grupos con nuevas miradas, hasta la fecha no han destacado por ser exhaustivos sobre el proceder político de los grupos "contrarrevolucionarios». Su participación en las conspiraciones que dieron lugar a los juicios, provocó que la documentación que podría arrojar luz sobre sus movimientos, nunca existiera o fuera eliminada para evitar represalias. Entre los especialistas que sí se han centrado en el grupo contrario al cambio político destaca Mariano Schlez que reflexiona:

«...el balance ha dado cuenta, no sólo de la exigua cantidad de trabajos dedicados a la actuación política de los contrarrevolucionarios, sino también de un escaso desarrollo en términos de la dilucidación de sus intereses sociales, dado que, en numerosas ocasiones, los estudios de comerciantes coloniales no hicieron

\footnotetext{
${ }^{6}$ Archivo general de la República Argentina. Tomo IX-X: Periodo de la Independencia, causa de Álzaga 1812. Buenos Aires: Kraft, 1897.

7 Hacemos referencia a los trabajos de TERNAVASIO, Marcela, Gobernar la revolución. Poderes en disputa en el Río de la Plata, 1810-1816. Buenos Aires: Siglo XXI, 2007 o la ya citada I. Polastrelli.

${ }^{8}$ CANDIOTI, M. Ley, justicia y revolución. La justicia en la ciudad de Buenos Aires. 1810-1821. Las Tesis del Ravignani [en línea]. .2015, n. 4, p. 9. [Consulta: 15-07-17]. Disponible en <http://www.ravignanidigital.com.ar/tms/series/tesis_ravig/ltr-004-tesis-candioti-2010.pdf>.
} 
hincapié en los aspectos materiales de su desarrollo»9 ${ }^{9}$

Incluso si revisamos los estudios realizados sobre los peninsulares que sí dieron apoyo al proceso revolucionario advertimos que son paradigmáticos los silencios (o asimilación criolla) sobre dos comerciantes-políticos destacados, vocales de la Junta, como son Domingo Matheu y Juan Larrea ${ }^{10}$.

Centrándonos en los estudios especializados que utilizamos para los juicios de Álzaga, y por tanto de Sentenach, podríamos diferenciar dos tipos. Por un lado las obras de Enrique Williams Álzaga, descendiente de M. de Álzaga, sitúa a este personaje como propulsor del movimiento independentista de Buenos Aires ${ }^{11}$. Aunque algunas de sus premisas son cuestionables, la contextualización política de sus textos nos proporciona una gran visión panorámica. Además, contamos con las nuevas aproximaciones sobre la política contrarrevolucionaria entre las que destacamos a Mariana Pérez ${ }^{12}$, Mariano Schlez, y añadiríamos los análisis sobre la infidencia de Irina Polastrelli ${ }^{13}$.

Al existir reproducciones de los expedientes y análisis de los juicios de 1809 y 1812, se ha hecho necesario reconstruir el de 1807 por medio de algunas cartas de personajes que se vieron afectados y/o opinaron sobre él, ordenanzas oficiales y la explicación que en el juicio de 1809 hizo el propio Sentenach sobre el anterior proceso. Pese al poco interés que ha despertado dicho juicio, creemos que su trascendencia fue notable.

\subsection{Felipe de Sentenach, una aproximación a su trayectoria}

Creemos importante trazar unas breves líneas sobre la biografía de este personaje a modo de introducción al propio proceso histórico. No tenemos muchos datos sobre la juventud de Felipe Sentenach (también mencionado como Santanach, Sentenac,...) y Marigó, pero sí sabemos que nació o vivió su infancia/juventud en Barcelona, que debió nacer alrededor de 1780 y que en 1810 su familia estaba

\footnotetext{
9 SCHLEZ, M. Los circuitos comerciales tardo-coloniales. El caso de un comerciante monopolista: Diego de Agüero (1770-1820) [tesis doctoral]. Buenos Aires: Universidad de Buenos Aires, 2014, p. 4.

10 GALMARINI, H. La situación de los comerciantes españoles en Buenos Aires después de la revolución de mayo 1810. Revista de Indias. 1984, n. 173, pp. 273-290.

${ }^{11}$ ÁLZAGA, Enrique. Documentos relativos a la actuación de Martín de Álzaga en la Reconquista y en la Defensa de Buenos Aires (1806-1807). Buenos Aires, 1948; ÁLZAGA, Enrique. Dos revoluciones. $1^{\circ}$ de Enero 1809-25 de Mayo 1810. Buenos Aires: Emecé, 1963; ÁlZAGA, Enrique. Fuga del General Beresford, 1807. Buenos Aires: Emecé Editores, 1965; ÁLZAGA, Enrique. Álzaga, 1812. Buenos Aires: Emecé Editores, 1968; ÁLZAGA, Enrique. Martín de Álzaga en la reconquista y en la defensa de Buenos Aires 1806-1807. Buenos Aires: Emecé Editores, 1971; ÁLZAGA, Enrique. Martín de Álzaga. Cartas (1806-1807). Buenos Aires: Emecé Editores, 1972 y ÁLZAGA, Enrique. Vida de Martín de Álzaga. Buenos Aires: Emecé Editores, 1984.

12 PÉREZ, M. ¡Viva España y mueran los patricios! La conspiración de Álzaga de 1812. Americanía. Revista de Estudios Latinoamericanos. Nueva Época. 2015, n. especial, pp. 21-55.

${ }^{13}$ Entre otros artículos destacaremos: POLASTRELLI, I. La disidencia política y sus condenas. Los juicios a Martín de Álzaga, 1809-1812. En: TEJERINA, Marcela (comp.). Definir el otro. El Río de la Plata en tiempos de cambio (1776-1820). Bahía Blanca: EDIUNS, 2012, pp. 45-72 y el ya mencionado: POLASTRELLI, I. Faltando a los deberes de buen vasallo. Op. cit.
} 
formada de su padre y su hermana ${ }^{14}$, sin que conste si anteriormente tuvo más hermanos. Sabemos que tuvo formación de matemáticas en Barcelona y que en 1801, con 21 años, intentó postularse como miembro académico de número en la Real Academia de las Ciencias y las Artes de Barcelona, solicitud que fue desestimada por el Revisor en la Dirección de Algebra y Geometría, Felipe de Amat. Según su informe, del 3 de abril de 1802, en el «Discurso Matemático» que presentó Sentenach (aquí escrito como Santanach) para su acceso, lo hizo «suponiéndose dicho sugeto admitido ya en el Cuerpo de la Academia manifiesta su reconocimiento, junto con sus buenos deseos de corresponder debidamente a semejante honra» ${ }^{15}$.

Pocas referencias tenemos de él hasta el 1 de julio de 1804, fecha de la que data el «Expediente de solicitud de licencia de embarque de Felipe Santenach y Marigó, natural y vecino de Barcelona, hijo de Felipe Santenach y de María Santenach y Marigó, para pasar a Buenos Aires, a establecer una tienda de comercio»16, llegando a Montevideo en noviembre de ese año. Su idea era instalar una firma comercial entre Paraguay y Buenos Aires con su amigo, Santiago Olibella y Jordán. Los dos viajaron al Paraguay «...donde habiendo quedado éste (Olibella) allí regresó (Sentenach) a los cuatro o cinco meses a esta capital con el ánimo de entablar su giro entre los dos lo que no llegó a verificarse por razón de que a poco tiempo fue cuando tomaron los ingleses esta capital» ${ }^{17}$.

\section{Las invasiones inglesas, el punto de partida ${ }^{18}$}

Iniciaremos nuestro análisis en agosto de 1806 con el proceso de reconquista de la capital virreinal, ocupada durante 40 días por 1.500 soldados ingleses. Esta recuperación se pudo lograr gracias a la acción combinada exterior e interior. Desde Montevideo, intervinieron las tropas lideradas por Santiago de Liniers compuestas por militares del fijo y dos grupos de milicianos, el de catalanes y el de los corsarios. Cabe destacar la efervescencia de ánimos y la lata participación ciudadana montevideana.

Pero más remarcable para nuestro estudio será la disidencia interior. En la propia capital se crearon unidades de resistencia a las tropas inglesas. Inicialmente fueron acciones individuales que paulatinamente se fueron organizando, creándose grupos cada vez más numerosos de sabotaje a la espera de la llegada de las tropas del exterior. En estos grupos destacó la llamada «junta de los catalanes» liderada por Sentenach y Esteve y Llach y auspiciada económica y políticamente por Álzaga

\footnotetext{
${ }^{14}$ Carta de su padre (Barcelona, 24 de octubre de 1810). AGN, Sala IX, caja 15-02-12, División colonia, Sección Gobierno, Pertenencias extrañas, varios años.

${ }^{15}$ Arxiu de la Reial Academia de Ciencies i Arts de Barcelona, 73.24 (ARACAB).

${ }^{16} \mathrm{AGI}$, ES.41091.AGI/23.15.2206//INDIFERENTE,2136,N.5, (01-07-1804).

17 Biblioteca de Mayo. T.XII. Sumarios y expedientes. Op. cit., p. 127.

18 Dada la extensión del presente artículo no haremos un análisis exhaustivo del contexto por el cual se iniciaron las invasiones inglesas ni porqué se perdió rápidamente la capital virreinal. Para un sucinta contextualización al conflicto y a los protagonistas: MARTíNEZ, D. Aproximación a los voluntarios catalanes en la Defensa y Reconquista de Buenos Aires (1806-1807). En: DALLA-CORTE, G.; PIQUERAS, R. y TOUS, M. (coords.). Construcción social y cultural del poder en las Américas [en línea]. Barcelona: Fundació Casa Amèrica Catalunya, 2015, pp. 88-103. [Consulta: 04-05-2017]. Disponible en <http://www.americat.cat/es/construccion-social-y-cultural-del-poder-en-lasamericas es>.
} 
y el Cabildo. Su actuación se ciñó a dos planes de acción. Por un lado, el reclutamiento $^{19}$ de un gran número de fuerzas para la resistencia, que fue acompañado de la creación de un pequeño campamento en la chacra de Perdriel donde guardaron armas, provisiones y de concentraron milicianos para una pronta ayuda a las tropas llegadas desde Montevideo. Y por otro lado, la excavación de dos túneles en la ciudad para minar el Fuerte y el cuartel de la Ranchería donde residían las fuerzas británicas, que no se llevó a cabo debido a la llegada de las fuerzas de Liniers a las cuales se unieron aún con grandes reticencias.

Pese a la buena disposición de aquellos vecinos porteños que participaron de los actos de la junta de los catalanes cabe destacar, por la incidencia que tendrá en los procesos posteriores, las oposiciones internas de Juan Vázquez Feijoo y Juan Trigo. Aunque se añadieron a la preparación de la resistencia, nunca formaron parte de la cúpula por su conocida desorganización, corrupción y falta de discreción. Como los dos esperaban sacar beneficio de estos actos, al verse relegados llegaron a quejarse ante Álzaga.

El 12 de agosto de 1806 culminó la ya conocida como «Reconquista». En espera de un segundo ataque de los ingleses, que bloqueaban la entrada del río, las autoridades militares ${ }^{20}$ reorganizaron a los grupos de ciudadanos preparados para la lucha contra los ingleses, fomentando y llegando a exigir la adhesión del resto de vecinos. Además se dispuso generar grupos por «territorios» de nacimiento, tanto peninsulares como americanos ${ }^{21}$. Esto dio a los criollos y las capas populares peninsulares acceso a las armas y al poder político efectivo ${ }^{22}$. Será partir de este proceso como la influencia miliciana en las decisiones políticas de la capital se hizo indispensable para las autoridades. El proceso de militarización del territorio, de las ciudades en ambas orillas del río y en definitiva la consolidación de los ciudadanos en armas son para muchos autores un verdadero signo de revolución ${ }^{23}$. Este proceso vino acompañado de un sentimiento de autonomía en la población, tanto criolla como peninsular, frente a las autoridades virreinales que no habían podido defenderlos. Una consecuencia directa fue que la combinación de fuerza efectiva y

19 Utilizando un sistema de reclutamiento donde 5 personas reclutaban, normalmente entre sus paisanos y conocidos, a 5 más, que a su vez reclutaban a 5 , hasta 5 niveles. impidiendo que los más bajos supieran realmente quiénes eran los líderes.

20 El Cabildo Abierto del 14 de agosto de 1806 sustrajo la atribución de Comandante de Armas al virrey Rafael de Sobremonte y fue traspasada a Santiago de Liniers.

${ }^{21}$ La historiografía argentina marca a Liniers como el instigador de esta iniciativa, aunque realmente hay un petitorio de los comerciantes catalanes, anterior a dicha proclama, donde piden organizarse en una milicia de coterráneos. MARTíNEZ, D. Aproximación a los voluntarios catalanes..., Op. cit., p. 11.

22 SÁBATO, $\mathrm{H}$. "Cada lector es un brazo armado». Apuntes para una historia de las milicias. En: BONAUDO, Marta; REGUERA, Andrea y ZEBERIO, Blanca (coord). Las escalas de la historia comparada. Op. cit., p. 109.

23 Para una aproximación a este proceso: DI MEGLIO, G. (2006). “Os habéis hecho temibles». La milicia de la ciudad de Buenos Aires y la política entre las invasiones inglesas y el fin del proceso revolucionario, 1806-1820. Tiempos de América: revista de historia, cultura y territorio [en línea]. 2006, n. 13, pp. 151-166. [Consulta: 07/06/17], Disponible en <http://www.raco.cat/index.php/TiemposAmerica/article/view/105689/163950 >; HALPERIN, T. Revolutionary militarization in Buenos Aires 1806-1815. Past and Present. 1968, n. 40, pp. 84-107 y RABINOVICH, Alejandro. La société guerrière. Pratiques, discours et valeurs militaires dans le Rio de la Plata (1806-1852). Rennes: Presses universitaires, 2013. 
autoconfianza inició una conflictividad que llevaría a una ardua lucha por el poder.

El 17 de agosto la junta de los catalanes de Sentenach, dado que su grupo no se adscribía a un territorio, pidió permiso al Cabildo para constituirse en un cuerpo llamado los Patriotas de la Unión ${ }^{24}$, agregado al Real Cuerpo de Artillería. Ya con su nombre quisieron dejar claro que reunía tanto a peninsulares como criollos, bajo el liderazgo de Sentenach y Esteve y Llach como primer y segundo comandantes y el del resto de la cúpula de la junta como oficiales. Los conocimientos matemáticos de Sentenach y el hecho de que la artillería fuera un arma poderosa y en renovación llevaron al Cabildo a promocionarlos rápidamente. Pese a esta disposición capitular, destacaremos que desde la petición al Cabildo en el que tenía gran influencia Álzaga, hasta la aprobación por Liniers, Comandante de Armas, pasó un tiempo donde hubo un fuerte intercambio de misivas y presiones por la negativa del segundo a ceder a su formalización. Finalmente el 7 de octubre se autorizó su creación pero debieron reducir sus fuerzas a 455 hombres $^{25}$. Como ya comentamos, la influencia de las milicias, que representaban a la ciudad en armas, tras los primeros combates fue grande y rápidamente se convirtieron en un foco de interés para los grupos de poder, que buscaron reforzar sus posiciones con su apoyo.

\section{1807 , luchas personales que no lo son}

\subsection{Causas de la acusación}

A inicios de 1807 Montevideo cayó ante los ingleses sin que se enviara una ayuda efectiva y rápida desde Buenos Aires, más ocupada en sus intereses estratégicos y sus luchas internas ${ }^{26}$. Esto consolidó el distanciamiento real entre las dos ciudades. Como en la derrota estuvo implicado directamente el virrey Rafael de Sobremonte, que había huido rápidamente de la capital con la primera entrada de los ingleses, aumentó contra él la indignación de la población. Esto sirvió de excusa para que sus opositores convocaran una Junta de Guerra el 10 de febrero. En ella se decidió destituirlo del mando, dejando el militar a Liniers y el político-civil a la Real Audiencia, resquebrajando aún más las estructuras virreinales tradicionales. Por lo tanto, nos encontramos ante una sociedad rioplatense altamente conflictiva y con una capital que necesitaba prepararse militarmente ante un seguro ataque inglés. Es en este contexto en el cual se inicia el primer juicio.

Retrocediendo a enero de 1807, el Cabildo de Buenos Aires eligió a Martín de Álzaga como alcalde de primer voto. Esto provocó que aquellos capitulares vinculados al grupo reformista contrario, y a través de Manuel Mansilla y Francisco Belgrano, pidieran al aún virrey Sobremonte que no aceptara este nombramiento

24 SALAS, A. Crónica y diario de Buenos Aires: 1806 Y 1807. Vol. I. Buenos Aires: Biblioteca Nacional, 2013, p. 282.

${ }^{25}$ MARTI, Pedro, Historia de la artillería argentina, Buenos Aires: Comisión del Arma de Artillería «Santa Bárbara», 1982, p.117.

${ }^{26}$ MARTíNEZ, David. Los ingleses no son el único enemigo. Las luchas internas en el virreinato del Río de la Plata a través de dos juicios, EN: DALLA-CORTE, Gabriela; GARZA, Gustavo; PIQUERAS, Ricardo y ZAIDENWERG, Cielo. (coord). Ciencias sociales, humanidades y derecho: Cómo pensar el mundo latinoamericano. [En línia] Barcelona: UB - UNA México, 2017. [Consulta: 12/07/17], Disponible en: <https://dialnet.unirioja.es/servlet/libro?codigo=698016>, pp.85-92. 
porque Álzaga:

«...tiene la predominación del nuevo cuerpo de artilleros que paga el Cabildo, cuyos jefes principales son todos su hechura y alguno su dependiente, que es consiguiente trate de realzar éstos a su devoción de que parece es hechura, y resultarán consecuencias que es preciso precaver en nuestros Patricios, a quienes se les mirará sin duda los últimos» ${ }^{27}$.

La acusación, aunque posteriormente fue retirada, demoró la ratificación de los cargos capitulares hasta el 2 de febrero, mostrando claramente el nivel de enfrentamiento dentro de las propias instituciones. Pero el panorama se complicó mucho más tras la deposición de Sobremonte, ya que en junio de ese año la Real Audiencia eligió a Santiago de Liniers como nuevo virrey interino ${ }^{28}$. Lo que en un principio podría haber sido una colaboración positiva para la sociedad virreinal entre Álzaga y Liniers, acabó consolidando dos bloques de influencia sobre los cuales orbitaron no sólo las fuerzas del propio sistema virreinal sino también aquellas de nuevo cuño generadas por las invasiones inglesas, con sus propios intereses, filiaciones familiares y económicas. Así, mientras que Álzaga representaba a los grupos vinculados al monopolio comercial, Liniers se apoyó en las fuerzas que no lo estaban, criollas y peninsulares. Remarcamos que estas últimas se fueron aprovecharon de su posición de fuerza para aumentar su autonomía y poder, ganando espacios anteriormente vetados. Veremos cómo los enfrentamientos entre estos dos grupos crecieron y eclosionaron en la proclamación de la Junta de Mayo, que en menos de dos años acabaría con las vidas de los dos líderes.

En este ambiente se produjo el hecho que inició el primer juicio y que creemos que no sólo respondió a una oposición personal entre acusado y acusador, sino que fue aprovechada como una pieza más en el conflicto entre grupos de poder. Todo empezó el 17 de febrero de 1807, cuando Sentenach instó a su tropa a continuar los entrenamientos que estaban realizando en el Parque de Artillería de Retiro. Lo que no se esperaba era que:

«...con ocasión de haber arrestado (...) a su segundo don Gerardo Esteve y Llach, don Juan de Dios Dozo, don José Miguel de Ezquiaga y don José Franci a resultas de haberle faltado a la subordinación en términos de incitar o aconsejar a la tropa para que no le obedeciese a tiempo de ir a hacer ejercicio, cuyo arresto con precedente queja que dio el confesante al excelentísimo señor virrey se les impuso por el señor mayor de esta plaza de resultas de este acaecimiento (...) le levantaron calumnia.... ${ }^{29}$.

Sentenach fue acusado de «haber formado la rebelión (...) contra su majestad ${ }^{30}$, o infidencia, la cual podía conllevarle la pena la muerte. Desconocemos las causas directas de las acusaciones de estos oficiales contra Sentenach pero sabemos que Francisco Agustini, comandante del Real Cuerpo de Artillería, se lo

\footnotetext{
${ }^{27}$ Biblioteca de Mayo. T.XII. Sumarios y expedientes. Op. cit., p. 71.

${ }^{28}$ Según una Real Orden, la Real Audiencia nombraría al militar con mayor graduación, siéndolo Liniers tras su ascenso y el aprisionamiento del Gobernador de Montevideo Pascual Ruiz Huidobro.

${ }^{29}$ Biblioteca de Mayo. T.XII. Sumarios y expedientes. Op. cit., pp. 127-128.

30 lbídem, p.121.
} 
comunicó rápidamente a Liniers e inmediatamente se inició la maquinaria procesal ${ }^{31}$. Muy pronto se advirtió que tanto el acusador como el acusado contaban con poderosos protectores, Liniers y Álzaga respectivamente, que intentaron jugar sus cartas. Así podríamos deducir que por influencia de Liniers, Sentenach acabó en prisión con un centinela, mientras que Esteve y Llach fue conducido a su domicilio ${ }^{32}$, los dos a la espera de juicio. Es interesante ver cómo paulatinamente fue surgiendo una rumorología sobre este enfrentamiento que rápidamente acabó fusionándose con otros conflictos de la ciudad, aumentando su importancia o implicación, tal y como muestran los siguientes hechos:

«Anoche le tiraron a Liniers dos balazos en la calle, y uno le acertó a su negro. Hoy ha resultado el mencionado arresto [Sentenach], y me dijo un sujeto, era por conspiración. Si es así habrá una jarana que no nos entenderemos el Virrey y sus áulicos causados por una parte, Sentenach y los suyos por otra; pierna los ingleses y portugueses y en cuarto lugar nuestra anarquía» ${ }^{33}$.

Así mismo, como la denuncia a Sentenach coincidió con la fuga del general inglés W. C. Beresford (oficial en jefe británico prisionero en la primera invasión e internado a Catamarca), al cual le había ayudado a escapar un miliciano de los Patriotas Unión, se dio por hecho que el traidor había sido Sentenach. Pronto se supo de su inocencia, confirmados como culpables el criollo Saturnino Rodríguez Peña, capitán de la $7^{\circ}$ compañía de los Patriotas, y Manuel Aniceto Padilla ${ }^{34}$.

\subsection{La causa}

Al no existir un texto único y claro sobre este juicio, usaremos con mucha cautela las informaciones encontradas, algunas de ellas posteriores al proceso, ya que pueden resultar parciales. Conocemos que las diligencias de la causa se iniciaron después del 3 de marzo de 1807, cuando la Comandancia de Armas pasó a la Real Audiencia las 81 foxas útiles que tenía sobre la denuncia. ${ }^{35}$ Tras permanecer en las Casas de Oruro ${ }^{36}$ (calabozos en Buenos Aires, creados para los cabecillas de la rebelión de Oruro de 1781$)^{37}$, Sentenach fue enviado a Mendoza ${ }^{38}$ con la vigilancia del teniente de infantería Mariano Gazcón/Gascón ${ }^{39}$. No se sabe si el inicio precipitado del viaje se hizo intencionadamente o no, pero sí que esto benefició enormemente al acusador. Entre el 25 y 29 de mayo se produjo un cruce de misivas entre la Real Audiencia y Santiago de Liniers, que intercedía por Llach, para saber

\footnotetext{
${ }^{31}$ Según la declaración de Esteve y Llach del 18/05/1809, durante el segundo juicio, el comentario de Sentenach fue: «si les parecía se podían pasar a la otra banda para incorporarse con el excelentísimo señor virrey marqués de Sobremonte y otros que se podían ir con su gente a los indios y levantarse con ellos organizando allí un ejército» (Biblioteca de Mayo. T.XII. Sumarios y expedientes. Op. cit., p. 117).

32 SALAS, A. Crónica y diario de Buenos Aires. Op. cit., vol. 2, p. 113.

33 Ibídem, p. 116.

34 WILLIAMS, E. Fuga del general Beresford, 1807. Buenos Aires: EMECE, 1965, pp. 137-138.

${ }^{35}$ AGN, Sala IX, caja 01-08-04, Comandancia general de armas.

${ }^{36}$ ANÓNIMO. Diario de un soldado. Buenos Aires: Ministerio del Interior, 1960, p. 149.

37 LESSER, R. Los orígenes de la Argentina: historias del Reino del Río de la Plata. Buenos Aires: Biblos, 2003, p. 251.

38 Biblioteca de Mayo. T.XII. Sumarios y expedientes. Op. cit., p. 401.

39 lbídem, p. 127.
} 
«...si podrá concederse la libertad bajo fianza al $2^{\circ}$ Comandante del cuerpo de la Unión Sr Gerardo Esteve y Llach, mediante a no podérsele seguir su causa por la ausencia del primero» ${ }^{40}$. Dado que «no puede poner en estado con arreglo a ordenanzas» el caso de Sentenach, Liniers consideró que Esteve y Llach debía ser liberado, para evitarle perjuicios. Así fue como Esteve y Llach volvió inmediatamente a su cuerpo de los Patriotas y lo comandó activamente en la defensa de la capital durante la segunda invasión inglesa. Prueba de ello son los expedientes militares emitidos por él mismo ${ }^{41}$ así como el premio real (introducción y extracción de efectos del país, libres de derechos) que recibió por sus acciones ${ }^{42}$. Desde el retorno de Esteve y Llach al cuerpo, los Patriotas de la Unión dejaron de estar vinculados al Cabildo para pasar a la órbita de Liniers. Este dio el paso definitivo a finales de 1808 cuando mandó a la Real Hacienda pagar los sueldos de los Patriotas, cosa que desde su creación había hecho el Cabildo ${ }^{43}$.

De todo este proceso el gran perjudicado fue Sentenach. Tras la victoria frente a los ingleses del 5 de julio de 1807, no se le permitió volver a su casa para ser juzgado. Además, parece que el proceso se inició, no sabemos exactamente cuándo, sin estar él presente, lo que provocó que el 1 de enero de 1808, desde Mendoza enviara un petitorio al Cabildo para que se le siguiera la causa en Buenos Aires ${ }^{44}$.

\subsection{Fin del juicio y consecuencias}

El 27 de abril de 1808 Sentenach obtuvo el permiso para volver a Buenos Aires donde el tribunal falló a su favor ${ }^{45}$. El 11 de octubre escribió al virrey interino Liniers para que, una vez la sentencia fuera firme, se le devolviera a los Patriotas de la Unión «cuerpo militar que reuní y organicé hasta ponerlo en estado de poder ser útil»» ${ }^{46}$ con su grado de teniente coronel y se le vindicara ante el resto de grupos milicianos y en los territorios. Propuso que quedara Esteve y Llach como primer comandante, lo que de facto ya estaba ejerciendo, para que él pudiera centrarse en «una Comisión del Real Servicio ${ }^{47}$ que le habían encomendado e «ir a establecer una fábrica de pólvora en la de Cochabamba» ${ }^{48}$. La insistencia en una vindicación general no es casual ya que, como dice el propio Sentenach a Liniers, la falsa acusación que se le hizo era «la más horrible» de la sociedad virreinal. Por eso sorprende que el uso de un falso testimonio de esta magnitud no significara ningún perjuicio, más bien al contrario, para Esteve y Llach. El capitán Vicente de Carvallo, defensor de Sentenach en la causa de 1809, analiza así la sentencia de este primer litigio:

\footnotetext{
40 lbídem.

${ }^{41}$ AGN, Sala IX, caja 26-06-12, Expedientes militares: C-F.

${ }^{42}$ AGN, Sala IX, caja 26-07-06, Invasiones inglesas- Promociones y quejas.

${ }^{43}$ MALLIE, Augusto (comp.). Acuerdos del extinguido cabildo de Buenos Aires, Serie IV - Tomo III. Buenos Aires: Senado de la Nación, 1927, p. 278.

${ }^{44}$ Ibídem, p. 60.

${ }^{45}$ Biblioteca de Mayo. T.XII. Sumarios y expedientes. Op. cit., p. 127.

${ }^{46}$ AGN, Sala IX, caja 01-08-04, Comandancia general de armas.

47 lbídem.

48 Biblioteca de Mayo. T.XII. Sumarios y expedientes. Op. cit., p. 127.
} 
«...su excelencia [Liniers] le colocó [Esteve y Llach] en el empleo de Sentenach sin embargo de no considerarse vacante, y debiendo éste ser repuesto en él, según las reales ordenanzas militares. Pero como Llach lejos de sufrir pena de infamia, y la de muerte, que es el castigo de su crimen prevenida en los artículos 10 título 17, tratado 2 - 84 y 85, título 10 tratado 8 de las mismas, saliese premiado, viéndose poco seguro en el empleo de Sentenach, repitió contra éste otra falsa acusación [la de 1809]»49.

Sentenach no solo fue afectado por el juicio en sí, también sufrió por los conflictos administrativos entre Liniers y el Cabildo por los sueldos que debía percibir en el tiempo que permaneció en prisión. El 17 de noviembre de 1808 Liniers zanjó la disputa con el argumento de que se le debía pagar como si «se hubiese hallado enfermo»50. Tras lo cual los cabildantes:

«...acordaron que por el Tesorero de Propios se le satisfagan los dos mil seiscientos doce pesos, tres y cuartillo reales corrientes, á que asciende el todo de su haber por prest, y gratificación de caballo, y montura (...) desde nueve de Febrero de mil ochocientos siete (en cuya fecha se le avenaron los vencidos desde la creación del Cuerpo) hasta treinta y uno de octubre último, en que cesó por parte de este Excelentísimo Ayuntamiento el abono de pagas al todo de los individuos Patriotas (hoy á cargo de la Real Hacienda)» 51 .

Si añadimos a este primer juicio los enfrentamientos que posteriormente mantuvo Esteve y Llach con el Cabildo (y que veremos en el siguiente punto) evidenciamos que lejos de ser un simple conflicto personal, todo el proceso formó parte de una confrontación mayor. Como ya hemos comentado, este juicio ha sido poco analizado por la historiografía rioplatense, incluso obviado, aunque fuera la base del juicio de 1809. Lo que resulta paradójico es que en la mayoría de los análisis realizados sobre las invasiones inglesas o sus protagonistas, este cambio de liderazgo en los Patriotas de la Unión no se haya destacado. Es cierto que en tiempos de conflicto la reorganización interna de un grupo puede ser algo normal, pero como hemos ido demostrando para este caso, el entorno político jugó una baza muy importante para provocar este cambio y en la resolución del juicio. De no ser analizado con amplias miras, no se entiende el posicionamiento de los Patriotas en los posteriores acontecimientos. Tampoco comprenderíamos la opinión de Cornelio Saavedra en 1809 cuando definió a Esteve y Llach como uno de «Mis compañeros de armas...»52, o su participación en las votaciones del decisivo 22 de mayo de $1810^{53}$ que daría lugar al fin de la organización virreinal.

\section{Posicionamientos en tiempos de guerra}

Para mostrar el nivel de conflictividad política en Buenos Aires, nos serviremos de las actividades de los Patriotas de la Unión para analizar la oposición entre

\footnotetext{
49 Ibídem, p. 401.

50 MALLIE, Augusto (comp.). Acuerdos del extinguido cabildo de Buenos Aires. T.III. Op. cit., pp. 307308.

51 lbídem.

52 SAAVEDRA, C. Memoria Autógrafa, Biblioteca de Mayo. Colección de obras y documentos para la historia argentina. T.II. Buenos Aires: Senado de la Nación, 1960, p. 26.

${ }^{53}$ MALLIE, Augusto (comp.). Acuerdos del extinguido cabildo de Buenos Aires. T.IV. Op. cit., p. 146.
} 
Álzaga-Cabildo y Liniers-Virrey, mientras Sentenach, preso, esperaba su sentencia. En junio de 1807, aún en lucha contra los ingleses, se inició un combate epistolar entre Esteve y Llach y el Cabildo por el pago de 455 uniformes para los Patriotas por el importe de 6000 pesos que Llach se ofreció a adelantar el 27 de junio de $1807^{54} \mathrm{y}$ por el cual el Cabildo estuvo pidiéndole cuentas más allá del mes de diciembre. Este presentó una cuenta por valor 3021 pesos el 30 de noviembre:

«los SS.res teniendo consideración a que no es esta la clase de cuenta que con reiteración se le á exigido por el Señor Diputado Don Miguel Fernández de Agüero, y la que ha debido rendir con arreglo a lo acordado por este Cabildo» y le conminaron a que en el "preciso termino de ocho días rinda cuenta instruida, y documentada de los gastos hechos en uniformar al Cuerpo de su cargo» ya que «con la que ha rendido de ningún modo Satisfice a este Cabildo, a quien desde luego corresponde averiguar la inversión del dinero que desembolsó y haya de desembolsar al indicado fin»55.

El conflicto llegó a una teórica resolución el 20 de enero de 1809 (época relevante para el Cabildo de Álzaga, como ya veremos) ${ }^{56}$, al ordenar Liniers que «se evacue con la posible brevedad ${ }^{57}$ la deuda a Esteve y Llach.

Es importante para el decurso de los posicionamientos políticos, mencionar que aunque en mayo de ese año las alianzas en la Península habían cambiado, convirtiendo al enemigo inglés en aliado y al francés en enemigo, el clima de violencia en el Virreinato era generalizado. La conflictividad no sólo se debía a la política imperial sino que, la escalada de oposiciones en la propia ciudad también aumentó. Debido a este clima belicista, se decidió mantener a la población preparada para otro posible enfrentamiento en el Virreinato. Pero como el mantenimiento de las fuerzas ciudadanas en armas suponía una sangría para las arcas virreinales, la Junta de Guerra decidió dejar sin sueldo, pero en armas, a todos los cuerpos milicianos excepto a los Patricios (criollos liderados por Cornelio Saavedra) y a los llamados húsares de Pueyrredón ${ }^{58}$. Estas dos milicias, que aglutinaban a un elevado número de la población criolla, siguieron entrenando mientras el resto de grupos volvieron a sus quehaceres.

El 24 de setiembre de $1808^{59}$ Esteve y Llach fue citado con su cuerpo ante el Cabildo para pasar revista a sus tropas ${ }^{60}$. Sentado junto a los cabildantes se le aproximó Juan Antonio de Santa Coloma, sobrino del comerciante que fue tutor de Álzaga a su llegada a Buenos Aires, a finales del siglo XVIII, que le recriminó que hubiera reubicado a los soldados ingleses, desertores católicos, que tenía en una única compañía separándolos en varias. Esteve y Llach le respondió que eso

\footnotetext{
${ }^{54}$ MALLIE, Augusto (comp.). Acuerdos del extinguido cabildo de Buenos Aires. T.Il. Op. cit., p. 578.

55 Ibídem, p. 725.

${ }^{56}$ En las actas del cabildo del 6 de julio de 1810 aún hace mención de este conflicto.

${ }^{57}$ MALLIE, Augusto (comp.). Acuerdos del extinguido cabildo de Buenos Aires. T.III. Op. cit., pp. 428429.

58 BEVERINA, J. El Virreinato de las Provincias del Río de la Plata. Su organización militar. Buenos Aires: Círculo Militar; Biblioteca del Oficial, 1992, p. 350.

${ }^{59}$ AGN, Sala IX, caja 01-08-04, Comandancia general de armas.

${ }^{60}$ Que había reelegido a Martín de Álzaga como alcalde de primer voto a inicios de 1808.
} 
equilibraba mejor a los Patriotas y era un aliciente para que mejoraran el manejo del idioma. El cabildante le increpó que lo había hecho sin permiso del Cabildo y le argumentó que «en el Cuerpo no había otro Comandante que el Excelentísimo Cabildo». Lejos de quedarse en ese desencuentro, tras la revista a la tropa se personaron algunos sargentos del cuerpo con una demanda presentada contra los algunos oficiales por malos tratos. Esteve les comunicó que castigaría a los culpables según las Ordenanzas pero Santa Coloma, una vez enterado, siguió insistiendo en que todos esos recursos debían presentarse ante el Cabildo. Esteve explotó ante el comentario replicando que él no los reconocía como jefes, sólo al virrey «que es a quién pertenece». Santa Coloma, a su vez, amenazó que ante tal comentario el Cabildo podría dejar de pagar sus sueldos, ya que él era el cabildante comisionado para efectuar ese pago ${ }^{61}$. Sin amedrentarse Esteve le comunicó que «no faltaría quien lo hiciese». Días después, el 28 de setiembre ${ }^{62}$, Esteve denunció ante la autoridad militar la exigencia que le hizo el Cabildo para que le presentara informes de sus fuerzas, cosa que a su juicio sólo competía al Comandante de Armas. La situación es más rica en detalles pero sólo este apunte nos sirve para concluir como Esteve y Llach ya era un «hombre de Liniers», como quedará claro en los enfrentamientos del 1 de enero de 1809, que dieron lugar al segundo juicio.

\section{1809, la explosión de las luchas intestinas en el virreinato}

\subsection{El juntismo, pieza clave del momento}

Pese a que nos hemos focalizado en el ambiente crispado de Buenos Aires las oposiciones y violencias no eran exclusivas del Río de la Plata, se trataba de un proceso del que tomaba parte el escenario europeo y en especial, España: el Motín de Aranjuez (17 y 19 de marzo de 1808), la subida al trono de Fernando VII, el inicio de la ocupación francesa, las abdicaciones de Bayona (5 de mayo) y el nombramiento de José I Bonaparte como rey de España, modificaron totalmente el panorama político de la Península. Cuando la sociedad española se levantó contra la invasión francesa lo hizo alrededor de juntas territoriales que sirvieron para organizar política y defensivamente a los diferentes territorios, a falta de un gobierno central al que reconocieran como legítimo63. Estas juntas territoriales pronto quedaron encuadradas en una Junta Central, que daría paso al Ilamado Consejo de Regencia. Este movimiento juntero revolucionó, no solo la estructura política de la metrópoli, sino que también se proyectó a América. Con la desaparición de la base legal del pacto virreinal, la propia figura del rey, cada territorio americano hizo una relectura sobre cuál era la organización político-administrativa que servía mejor a sus intereses. Como la legalidad virreinal emanaba de diversas fuentes, todas las opciones que se plantearon fueron coherentes con el sistema, lo cual dio como

\footnotetext{
61 MALLIE, Augusto (comp.). Acuerdos del extinguido cabildo de Buenos Aires. T.III. Op. cit., p. 21.

62 AGN, Sala IX, caja 01-08-04, Comandancia general de armas.

63 Múltiples son las obras específicas dedicadas al movimiento juntero en España y América, pero destacaremos las siguientes que condensan una visión general al juntismo en los territorios de la América española: CHUST, Manuel (coord.). 1808. La eclosión juntera en el mundo hispano. México: FCE; Colmex, 2007; ÁVILA, Alfredo y PÉREZ, Pedro (coords.). Las experiencias de 1808 en Iberoamérica. México: UNAM; Alcalá de Henares: UAH, 2008 y los dossiers: PORTILLO, José María (coord.). 1808, Crisis y soberanía. Historia y Política. 2008, n. 19 y BREÑA, Roberto (coord.). Iberoamérica en 1810: Emancipación, autonomía y lealtad. Historia y Política. 2010, n. 24, entre otros.
} 
resultado que según cuál de ellas se utilizara la opción seguida se consideró «legítima» e «infidente» la contraria.

El 21 de septiembre de 1808 se constituyó una Junta Gubernativa en Montevideo, liderada por el gobernador Francisco Javier de Elío. Este proceso de subversión contra Buenos Aires fue consecuencia de la llegada simultánea de varias noticias de la península a Liniers que le anunciaron la subida al trono de Fernando VII, su posterior cautiverio y su sustitución por José I Bonaparte. Ante estos cambios, que no dejaban clara la situación política real de la península, el virrey interino decidió actuar con cautela y no alinearse. Esto no fue bien recibido en la sociedad rioplatense, lo que sirvió de excusa a Montevideo para desligarse de Buenos Aires, argumentando que no podían obedecer a un virrey francés. Igualmente, el Cabildo porteño aprovechó estas dudas para adelantarse a Liniers y forzar la jura a Fernando VII como rey legítimo «ausente». Así podemos deducir que tanto la actuación de Montevideo como el movimiento cabildante, liderado de nuevo por Álzaga, respondían a una misma idea, dinamitar el poder de Liniers. Además, tras la experiencia en la Banda Oriental, la idea de crear una junta porteña que desconociera a Liniers, empezó a tomar fuerza entre ciertos grupos de poder.

\subsection{Preparación del golpe}

Los sectores criollos y peninsulares que se habían situado alrededor de Liniers, habían ido ocupando el espacio tradicional de las antiguas oligarquías políticas y económicas del virreinato. Por eso, el grupo de Álzaga pronto se convenció de que para conservar el poder ganado durante las invasiones inglesas, no podía seguir las vías tradicionales del poder. No lo sabemos con certeza, pero deducimos que Elío y Álzaga decidieron proclamar una junta en Montevideo e intentar instalar otra en Buenos Aires, para reasumir el poder. Esto se pudo orquestar cuando el alcalde porteño pasó a la capital de la Banda Oriental ${ }^{64}$ mientras se encontraba de baja por motivos de salud ${ }^{65}$. Iniciada la insubordinación por Elío, parece que el plan era reproducir dicho movimiento en la capital virreinal, en octubre de ese año. Este plan no se llevó a cabo por la alarma que produjeron tanto el llamado ante Liniers del jefe del cuerpo de vascos, favorables a Álzaga, como el acuartelamiento de los Patricios, vinculados a Liniers. Paralelamente a la preparación del golpe juntista se llevó a cabo una dura campaña de desprestigio contra el gobierno de Liniers. Las acusaciones pasaron por la mención de actos de nepotismo, de fomentar el contrabando en su beneficio y privilegiar política y económicamente a los que lo rodeaban. Incluso se le criticó su vida personal, como su relación con Ana Perichón. Liniers les facilitó el trabajo cometiendo varias «torpezas» legales, como por ejemplo organizar la boda de su hija con «un francés advenedizo y notoriamente sospechoso»66, Juan Vandeuil Perichón, propuesta para el 26 de diciembre sin la licencia real correspondiente, según los cabildantes. O también el respaldo que dio a

\footnotetext{
64 LOZIER, B. Martín de Álzaga; historia de una trágica ambición. Buenos Aires: Editorial Ciudad Argentina, 1998, p. 149.

${ }_{65}$ Queda marcada su ausencia de inicios de abril a mediados de junio de 1808 en las reuniones capitulares, como vemos en MALLIE, Augusto (comp.). Acuerdos del extinguido cabildo de Buenos Aires. T.III. Op. cit. en las pp. 81-124.

66 VAZQUEZ, H. Santiago de Liniers. Madrid: Encuentro, 2012, p. 327.
} 
Bernardino Rivadavia para «la Plaza de Alférez Real ó Mayor Propietario», que denunció el Cabildo el 31 de diciembre de 1808 ya que «el Expediente (...) es del privativo y peculiar interés de este Excelentísimo Cabildo y que no debió haberse procedido en él sin su intervención, conocimiento, citación y audiencia: que en asuntos de esta clase recomiendan las Leyes la precisa audiencia de los Cabildos: que el auto adolece de (...) nulidad»67. Con este ambiente belicista finalizó el año 1808.

\subsection{La Asonada de Álzaga}

El golpe del 1 de enero de 1809 , conocido como «la asonada» 68 , es analizado frecuentemente como un simple intento de un ambicioso Martín de Álzaga junto a los peninsulares conservadores, por recuperar una sociedad rioplatense en la que los criollos ya despuntaban en los círculos de influencia y, relegarlos otra vez a su estado de dependencia. Alejandro Mackinnon, líder del comercio inglés en Buenos Aires en carta a George Canning, secretario de Estado del Departamento de Relaciones Exteriores de Gran Bretaña, definió a los golpistas como aquellos españoles que estaban relacionados con las «privilegiadas compañías de Cádiz, así como los catalanes y gallegos, hasta ahora han sido los principales usufructuarios del sistema»69. Sin descartar esta versión, veremos que el movimiento fue mucho más complicado.

En las elecciones al nuevo cabildo, en los primeros días de enero de 1809, los más votados fueron los vecinos que tenían una línea de actuación claramente «anti linieristas» encabezados por Álzaga. La lista de los elegidos debía ser aceptada por el propio virrey y por tanto se dirigieron al Fuerte donde se encontraba Liniers. Paralelamente a este trámite, en la Plaza Mayor se fueron congregando grupos de vecinos y milicia, que empezaron a gritar «Viva Fernando VII», y a pedir «junta como en España» para velar por los intereses del monarca legítimo y deponer el «mal gobierno» del «francés» 70 . Recordemos que el movimiento juntista se amparó en la ilegalidad de las instituciones de José I y la necesidad de re-organizarse por estar preso el rey. Como ya remarcamos, las dos opciones, la continuista, que quería mantener la organización vigente, y la juntista, se amparaban en un derecho virreinal vigente.

Un primer elemento que rompe con la visión tradicional del conflicto, el dualismo peninsulares monopolistas contra criollos, lo encontramos al analizar la composición de los «bandos» enfrentados, más heterogéneos de lo que ha permanecido en la memoria colectiva. Es cierto que el Cabildo se apoyó en los tercios de vascos, gallegos y catalanes $^{71}$, representantes de los grupos vinculados al comercio

\footnotetext{
67 MALLIE, Augusto (comp.). Acuerdos del extinguido cabildo de Buenos Aires. T.III. Op. cit., p. 400.

68 RAE (2017): «Reunión tumultuaria y violenta para conseguir algún fin, por lo común político».

69 TJARKS, G. O., El consulado de Buenos Aires y sus proyecciones en la historia del Río de la Plata. Vol. I. Buenos Aires: Universidad de Buenos Aires, 1962, p. 345.

70 Biblioteca de Mayo. T.XII. Sumarios y expedientes. Op. cit., p. 129.

${ }^{71}$ MARTÍNEZ, D. La comunidad catalana y la revolución de Mayo: algo más que comerciantes. En: DALLA-CORTE, G.; GARZA, G. y PIQUERAS, R. (coords.). Iberoamérica, España, Catalunya. Intercambios desde la Geografía y la Historia [en línea]. Barcelona: Edición Km 13.774; Fundació Casa Amèrica Catalunya, 2016, pp. 45-64. [Consulta: 02-07-2017]. Disponible en
} 
monopolístico, pero también encontramos a criollos, como Mariano Moreno secretario del Cabildo y líder radical de la Junta de 1810; al tercio de cazadores correntinos anexados al de vascos; también a miembros del cuerpo de Patricios, (José del Texo, capitán del primer batallón y José Domingo Urién del tercero) descontentos con el liderazgo personalista de Cornelio Saavedra ${ }^{72}$. Por lo que respecta a Sentenach, no está clara su ubicación exacta, pero igualmente quedó adscrito al grupo de los cabildantes.

Por otro lado estaba el grupo que orbitaba alrededor de Liniers aunque sin estar bajo su mando efectivo: los cuerpos criollos de patricios, húsares y arribeños, así como los peninsulares no adscritos al comercio monopolista, los andaluces y los cántabros o montañeses. Evidentemente nos encontramos con los Patriotas de la Unión de Esteve y Llach, que seguían a Saavedra (y no a Liniers). Esto muestra que aunque la figura de Liniers representaba a una de las facciones, ciertamente nunca tuvo un poder real sobre ella e incluso se podría llegar a decir que fue el grupo quien lo mantuvo en el poder ${ }^{73}$. Hemos de tener en cuenta que en el imaginario de la gran mayoría de la población porteña, Liniers había apoyado a los criollos y a los menos agraciados y, en cambio, Álzaga representaba a los privilegiados ${ }^{74}$. Así que este enfrentamiento no sólo se produjo por los intereses políticos, económicos, de liderazgo, personales y familiares de los dos cabecillas sino que nos volvemos a encontrar con la gran influencia de los intereses de las distintas fuerzas milicianas. Estas, protagonistas tanto de la sublevación como de la represión se habían convertido simultáneamente en jueces, árbitros y partes afectadas ${ }^{75}$.

Los intentos de presionar al virrey interino en el Fuerte y en la plaza acabaron tras un rápido movimiento político y militar del jefe de Patricios, Cornelio Saavedra, el cual impidió que Liniers firmara su renuncia e impuso a sus milicias, criollas y peninsulares, sobre las que estaban en la Plaza Mayor. Este relato, mitificado en su autobiografía, estuvo bien calculado pues contaba con una extensa red de espías ${ }^{76}$ que le hicieron prever su victoria. Una vez desbaratado el intento de golpe de forma casi incruenta, se inició una rápida represalia política contra todos los causantes: los capitulares, presos y expulsados el 4 de enero a Carmen de Patagones ${ }^{77}$; los tercios sublevados fueron desarmados, requisadas sus banderas y suprimidos sus méritos; los funcionarios, incluyendo al propio Cabildo, fueron depurados y se nombró a

\footnotetext{
$<$ http://americat.barcelona/uploads/20161124/lberoamerica Espan a Catalun a 2016.pdf >.

72 Según Fabián Harari, estos enfrentamientos internos en las milicias respondían a las discusiones sobre qué modelo tenían que seguir ante estos conflictos. Serás las decisiones tomadas y opciones elegidas, las que algunos autores identifican como la base de los futuros programas políticos que llevarán a la creación de los partidos políticos. HARARI, F. ¿Ampliación política o crisis orgánica?: un análisis del Cuerpo de Patricios, 1806-1810. Anuario del Instituto de Historia Argentina [en línea]. 2006, n. 6, pp. 12-13. [Consulta: 27-07-2017]. Disponible en $<$ http://www.fuentesmemoria.fahce.unlp.edu.ar/art revistas/pr.58/pr.58.pdf>

73 lbídem, p. 13.

74 PÉREZ, M. ¡Viva España y mueran los patricios! Op. cit., p. 45.

75 HALPERIN, T. Revolutionary militarization... Op. cit., p. 106.

76 SAAVEDRA, C. Memoria Autógrafa. Op. cit., p. 27.

77 M. de Álzaga, J. A. Santa Coloma, O. Reynals, F. de Neyra y Arellano y E. Villanueva. Antes de su llegada a prisión fueron liberados por F. J. de Viana, enviado por Elío y enviados a la Banda Oriental. Llegaron a Montevideo el 17 de febrero desde donde continuaron su oposición a Liniers por medio de denuncias (para la corte y la capital).
} 
nuevo personal adepto a Saavedra. Para el propio Liniers esta contundente acción pudo ser la venganza por la represión de Álzaga cuando fue alcalde de primer voto en 1795, contra la llamada conspiración de los franceses ${ }^{78}$. Las tropas se mantuvieron vigilantes en la plaza varios días para «garantizar la calma» y mostrar la fuerza de Saavedra y sus seguidores.

\subsection{El doble juicio}

Mientras los cabildantes marchaban a la cárcel de Patagones sin juicio, la Real Audiencia, con el beneplácito de Liniers, inició una causa sobre la asonada con el coronel de artillería Francisco de Agustini como fiscal responsable de la investigación. El 14 de enero todo se complicó cuando este advirtió a Liniers que tenía una segunda denuncia, hecha por Juan Trigo ${ }^{79}$, que no tenía que ver con la asonada y sí con la acción de los acusados durante la Reconquista, y quería «que la superioridad le oyera en cuerda separada ${ }^{80}$ ». Los denunció por "haber querido poner en independencia del dominio de nuestro soberano, a esta capital» ${ }^{81}$ utilizando comentarios como estos:

- «...si tenemos la fortuna de conseguir felizmente la reconquista hemos de establecer una mesa redonda en que todos seamos iguales y no haya alguno superior a los demás» ${ }^{82}$.

- «...no ceñir las miras a esa sola acción sino en pensar seguidamente en hacer esto feliz, que esta América era mejor que toda la Europa, y no necesitaba de ella para nada, antes bien ellos sí son los que necesitan de nosotros y no nos hacen caso para nada teniéndonos en el mayor abandono, y sin pensar en otra cosa que en sacarnos el jugo: (...) que era preciso sacudir un yugo tan pesado, e igualmente prender luego que se consiguiese la reconquista al señor virrey entonces marqués de Sobremonte, como así mismo al subinspector general don Pedro de Arze quien no hacía falta alguna, y que arrestados los dos después se vería lo que había de hacerse» ${ }^{83}$.

Lo oportuno de esta denuncia nos hace pensar cuán adecuado a los intereses del grupo de Liniers fue presentar una acusación de lesa majestad durante el proceso al grupo de Álzaga por la asonada. Además, utilizando acusaciones sobre $1807^{84}$, los mostraba como infidentes en un momento de necesaria reafirmación de la fidelidad para con la monarquía. De esta forma, se inició un doble juicio a Sentenach, a J. M. Ezquiaga (capitán de la $2^{\mathrm{a}}$ compañía de los Patriotas) y a Álzaga in absentia: uno por la asonada, con el fiscal Agustini, y otro por independentistas durante las invasiones inglesas, seguido por el capitán de fragata don Juan de Vargas. El 4 de febrero Sentenach fue apresado y enviado al cuartel de Arribeños por Vargas, «incomunicado y a mi disposición para la práctica de las diligencias (...)

\footnotetext{
78 PÉREZ, M. ¡Viva España y mueran los patricios! Op. cit., p. 45.

79 En el proceso de constitución de los Patriotas de la Unión de 1806, tanto a él como a Vázquez Feijoo se les quiso incluir, pero estos lo rechazaron por considerar que se merecían mayores cargos.

${ }^{80}$ Biblioteca de Mayo. T.XII. Sumarios y expedientes. Op. cit., p. 4.

81 Ibídem, p. 3.

82 lbídem, p. 19.

83 lbídem, p. 20.

84 Tal es así que el fiscal pidió el 15 de febrero que se le enviara la causa de 1807 (Ibídem, p. 392).
} 
todo sin perjuicio de procederse cuando oportunamente convenga al arresto de otros individuos que resulten indiciados en el mismo delito»85. Antes de iniciarse el proceso, tanto Sentenach como Ezquiaga ${ }^{86}$ reclamaron continuar bajo fuero militar ${ }^{87}$ y denunciaron a los fiscales de parcialidad, posiblemente para dilatar el proceso ante un posible cambio de virrey, pidiendo su remoción. Todo fue rápidamente desestimado. Liniers, paralelamente al juicio, presionó a Sentenach por otras vías: el 2 de junio ${ }^{88}$ escribió a Esteve y Llach, con copia a la Real Hacienda, para que se le rebajara su sueldo a la mitad hasta finalizar el juicio.

En cuanto a la participación real de Sentenach en la asonada, es controvertida. Mientras que unos, como el propio acusado y varios testigos (por ejemplo, Justo García Valdés, primer médico del ejército) ${ }^{89}$ afirmaron que este se encontraba en su domicilio ${ }^{90}$ y que al iniciarse el tumulto, salió acompañado de los hermanos Moreno (Mariano y Ramón) y Joaquín Correa, hacia el Cabildo donde se detuvo a hablar con sus conocidos y se volvió a casa; otros, en cambio, lo sitúan en medio del grupo de la asonada, organizando a las milicias en el Cabildo o mandando tocar la campana a revuelta ${ }^{91}$. Muchos testigos del juicio declararon contra Sentenach en base a rumores, como muestra la declaración de Francisco Romero:

«...estuvo en casa de Vásquez después de haber sucedido la conmoción del día primero del año para que éste le entregase unas certificaciones que le guardaba de sus méritos y servicios, y que en efecto habiéndose suscitado la conversación sobre aquella ocurrencia le dijo: que el oficial de artillería Sentenach había estado mandando o dando disposiciones a la gente armada que había en los corredores del Cabildo bajos la tarde del citado día ${ }^{92}$ ».

Aunque muchos estudios lo ubican con los asonados, por su cercanía personal, es cierto que no podemos descartar que su detención estuviera relacionada con las continuas luchas personales. Tomando esta premisa como base, compararemos el testimonio de Domingo Matheu (comerciante catalán, teniente del tercio de catalanes, que no participó en la asonada y que formó parte de la junta de 1810) sobre la represión del uno de enero en su propio domicilio...

«...entró una partida de treinta y tantos y al entrar me dijeron que fuera preso, y parecía según la furia con que entraron, que no sólo me venían a llevar, sino que querían saquear la casa; pero les pregunté cuál era el delito que había cometido para entrar de esa manera y querer llevarme preso; y me contestaron tener orden de su comandante para prender a todos los catalanes ${ }^{93}$

\footnotetext{
${ }^{85}$ Carta de J, de Vargas en Biblioteca de Mayo. T.XI: Sumarios y expedientes. Op. cit., p. 73.

${ }^{86}$ Biblioteca de Mayo. T.XII. Sumarios y expedientes. Op. cit., p. 125 y p. 141.

87 POLASTRELLI, I. La disidencia política y sus condenas. Op. cit., pp. 112-113.

${ }^{88}$ Biblioteca de Mayo. T.XII. Sumarios y expedientes. Op. cit., p. 421.

89 lbídem, p. 138.

90 lbídem, p. 128.

91 Ibídem, p. 29 (testimonio de J. V. Feijoo).

${ }^{92}$ Ibídem, p. 49.

${ }^{93}$ MATHEU, D. Autobiografía. Biblioteca de Mayo. Colección de obras y documentos para la historia argentina. T.III. Buenos Aires: Senado de la Nación, 1960, p. 61.
} 
...con lo que Sentenach atestiguaba en el juicio de $1809 \ldots$

«...que después de esto no habiéndose movido de su casa a eso de las tres de la mañana fue una partida del cuerpo de montañeses dirigida por un oficial o sargento del propio cuerpo a quien acompañaba el teniente de la Unión don Julián Corbera quien le dijo traían la orden de llevarlo preso, la que había recibido de don Gerardo Esteve y Llach, a lo que se prestó desde luego el confesante por hallarse enteramente inocente ignora al mismo tiempo el mérito que podía dar lugar a aquel arresto: que habiendo sido conducido al Fuerte lo pusieron en el cuerpo de guardia del oficial hasta la mañana siguiente en la que lo trasladaron al cuartel de arribeños en que se halla ${ }^{94}$.

Hasta la fecha, no tenemos una fuente "definitiva» que muestre exactamente qué fue de Sentenach el uno de enero. Dado que nuestra base documental la forman el propio expediente judicial y los comentarios encontrados en las biografías de los otros implicados escritas posteriormente a 1810, entendemos que hemos de ir con cuidado de no analizar el conflicto sólo desde un punto de vista.

A parte de estas problemáticas, también hemos de mencionar el conflictivo ambiente político del propio Virreinato mientras se celebraban las pesquisas para el juicio. En julio de 1809 Liniers fue depuesto como virrey por Baltasar Hidalgo de Cisneros, que rápidamente inició una política "conciliadora» para todos los grupos. El problema fue que dado el nivel de división social y política imperante provocó el efecto contrario al deseado. Dentro de las primeras medidas de Cisneros encontramos la disolución de la Junta de Montevideo, un olvido oficial para lo ocurrido el 1 de enero que se complementó con una amnistía para los acusados por la asonada que pudieron volver a Buenos Aires. Además y, de gran importancia para nuestro tema central, cerró esa causa judicial, dejando la de independencia vigente y removió a los fiscales que llevaban el caso, sustituyéndolos por el teniente de navío Domingo Navarro y el teniente de fragata Joaquín de Sagasti.

Los nuevos fiscales reiniciaron la causa por independencia, revisando las declaraciones y confrontando a los testigos con ellas. Sentenach siguió preso en el cuartel de Arribeños hasta enero de 1810 que pasó a su domicilio. De los 87 testigos que se entrevistaron en toda la causa, incluyendo al propio Esteve y Llach, muchos aclararon en esta segunda vuelta que los comentarios que habían oído a favor de la independencia, les habían llegado por terceras personas. La mayoría de esas voces, eran de personas vinculadas a Trigo y Feijoo o correspondían a otros intereses personales. Analizando estos testimonios, podríamos dibujar una red de relaciones tejida durante las invasiones inglesas y que se iba a poner en juego durante los movimientos revolucionarios de mayo de ese mismo año.

\subsection{La sentencia. Otra victoria amarga para Sentenach}

El juicio no solo pasó por un cambio de virrey, sino que el 25 de mayo de 1810 la política del Río de la Plata dio un giro radical con la instauración de una Junta Provisional Gubernativa, Ilamada popularmente Primera Junta. Con la llegada de las

\footnotetext{
${ }^{94}$ Biblioteca de Mayo. T.XII. Sumarios y expedientes. Op. cit., pp. 129-130.
} 
noticias que anunciaban la caída de la Junta de Sevilla en España, por el avance napoleónico, muchos vecinos protestaron en Buenos Aires porque, caída la soberanía en España, esta debía revertir «al pueblo». Según ellos, la base legal de la autoridad del virrey Cisneros había desaparecido, al caer la de España de la cual dependía su cargo. La semana del 18 al 24 de mayo estuvo llena de reuniones y debates en el Cabildo para analizar cuál era el sistema de gobierno más adecuado para el Virreinato. Recordemos que en estas reuniones no contaron con la figura de Álzaga, uno de los hombres más influyentes, pero sí de Esteve y Llach como jefe de milicias. El 25 de mayo, después de presiones para apartar a Cisneros de cualquier vínculo con el poder, se formó la Primera Junta. De sus nueve miembros, varios habían participado de una forma u otra en las invasiones y la asonada del 1809: el presidente de la Junta fue Cornelio Saavedra, los vocales Matheu y Larrea pertenecieron al tercio de catalanes ${ }^{95}$ y el secretario Mariano Moreno era conocido de Sentenach.

Pese al cambio de régimen, el juicio no se vio afectado en su esencia. Es cierto que los fiscales designados por Cisneros pidieron el 28 de mayo a las autoridades que les excusaran de sus funciones en el juicio por estar bajo jurisdicción de la Marina Real, y por tanto se debían al jefe del apostadero de Montevideo que era contrario a la Junta ${ }^{96}$. Esta, en consecuencia, nombró como fiscal a Pedro Durán, capitán graduado y ayudante mayor del regimiento de infantería.

Tras más de 18 meses de juicio, el 24 de julio de 1810 se procedió a dictar sentencia, haciéndola definitiva el 27. El Consejo de Guerra:

«... condena el consejo a don Juan Trigo, don Juan Vásquez Feyjóo y don Juan José López, a ser expatriados de esta capital sin que en tiempo alguno y por ningún pretexto puedan volver a ella inhabilitándolos para la obtención de todo empleo, público y de honor. Ha resuelto igualmente el consejo que el extranjero don Guillermo P. White sea expelido de estos dominios sin que por motivo alguno pueda, volver a ellos (...), que los acusados don Felipe de Sentenach, don Miguel de Ezquiaga y don Martín de Álzaga, sean puestos inmediatamente en libertad, haciéndose pública su vindicación e inocencia con arreglo a ordenanza: que don Felipe de Sentenach y don Miguel de Ezquiaga sean recomendados a su majestad para la indemnización de los perjuicios que han sufrido en la suspensión de sus empleos, igualmente que don Martín de Álzaga para que su soberana munificencia se sirva dispensarle las gracias que sean correspondientes al justo resarcimiento de los daños que debe haberle causado la presente causa, y sean también análogas a los dignos premios de que le han hecho acreedor sus importantes y distinguidos servicios: que a los dos primeros acusados don Felipe de Sentenach y don Miguel de Ezquiaga se les satisfagan por las respectivas oficinas los sueldos que hayan devengado durante su suspensión, y que el señor don Juan de Vargas primer fiscal en este proceso sea reprendido seriamente por los notabilísimos defectos que se advierten en las actuaciones practicadas por él $(\ldots){ }^{97}$.

${ }^{95}$ Fue purgado en 1809 de su puesto en el Consulado de Comercio, readmitido con la amnistía de Cisneros.

${ }^{96}$ Biblioteca de Mayo. T.XII. Sumarios y expedientes. Op. cit., p. 386, reiterado el 29 de mayo, pp. 388-389.

97 lbídem, pp. 538-539. 
Otra vez los verdaderos culpables en un juicio contra Sentenach tuvieron sentencias leves. El 26 de junio fue expulsado, por ser extranjero, uno de los acusados $^{98}$ pero Vázquez y Trigo consiguieron huir antes de aplicárseles. Los falsos testigos quedaron a disposición de los anteriormente acusados para poder ser denunciados por agravios, lo que Álzaga inició el 26 de julio demandando copia del expediente judicial para su uso particular. Aunque los tres falsamente acusados fueron puestos en libertad, no tuvieron ninguna recompensa. Pero si analizamos las votaciones previas a la sentencia hechas por el Consejo de Guerra, veremos cómo varios de los siete miembros, seis vocales y el presidente ${ }^{99}$, votaron por devolverle el cargo a Sentenach: de forma directa (Agustín de Arenas) o a discreción del gobierno (Martín Rodríguez, Florencio Terrada y Francisco Rodrigo). Pero seguramente, en el dictado final, prevaleció la idea de Juan Bautista Bustos de no hacerlo «por evitar nuevos males».

\section{1812, la justicia revolucionaria}

\subsection{La vorágine que todo lo afecta}

Los rápidos cambios del proceso revolucionario hicieron mella no sólo en sus opositores, sino entre sus propios adeptos. Hubo varios frentes de inestabilidad que les afectaron, por un lado, las luchas intestinas entre los propios revolucionarios, por otro la dura oposición de los territorios realistas (Montevideo y el Virreinato del Perú) y finalmente los conflictos derivados de la propia desestructuración territorial y política al enfrentarse muchas ciudades al centralismo porteño, como fue el caso del Paraguay. Un ejemplo de las medidas tomadas por la Junta para cerrar frentes de oposición, fue el fusilamiento de Liniers por encabezar en Córdoba la oposición a la junta porteña ${ }^{100}$.

A Sentenach la revolución lo encontró arrestado en su domicilio esperando la sentencia. Una vez dictada esta, como también pasó en el primer juicio con la fábrica de pólvora en Cochabamba, la justicia no le devolvió, de manera intencionada o por imposibilidad real, su cargo militar, pero las autoridades se lo compensaron indirectamente. El 8 de agosto, ya libre de cargos la Junta lo nombró, por sus «conocimientos, actividad y celo» director de la Academia de matemáticas, de nueva creación ${ }^{101}$. Esta estuvo ubicada en un local cedido por el Consulado de Comercio que también la subvencionaba, y fue auspiciada por Manuel Belgrano, que promovió esta iniciativa para consolidar la mejora de las ciencias prácticas en el territorio. Además, respondió a los ideales de inculcar «el principio de la ilustración de nuestros militares, y de la regeneración de esa brillante carrera, que una política destructora había degradado, sepultándola diestramente en las tinieblas de la

\footnotetext{
98 Biblioteca de Mayo. T.XII. Sumarios y expedientes. Op. cit., p. 540.

99 Presidente: Bernardo Lecocq; vocales: Juan Bautista Bustos, Agustín de Arenas, Martín Rodríguez, Florencio Terrada, Nicolás de la Quintana y Francisco Rodrigo.

100 Esta muerte significa la eliminación de una posible oposición a la Junta hecha por un personaje que aún contaba con una gran influencia y prestigio y que podría haber cohesionado a las fuerzas contrarias a la Junta.

${ }_{101}$ AGN, Sala IX, División colonia - Sección gobierno - Tomas de razón - 08-08-01.
} 
ignorancia»102. Así, la Academia nacía con una intencionalidad específica ${ }^{103}$, cosa que la diferenciaba de otros proyectos académicos. Se pretendía tanto preparar personal para la defensa del territorio como formar militares de carrera vinculados al espíritu de la Revolución. Este último aspecto rompía el espíritu «igualitarista» que habían generado las invasiones inglesas. En la Gazeta de Buenos Aires del 23 de agosto de1810 se imprimió el discurso inaugural de Belgrano y el de Sentenach, en el cual se definió cuál era la organización interna de la Academia y su plan de estudios $^{104}$. Hasta la fecha no hemos encontrado mucha información sobre ella, por lo que deducimos que los primeros años revolucionarios fueron tranquilos para Sentenach, pese a las disposiciones contra los peninsulares no identificados con la Junta. Es por eso que, aunque parezca que nos contradecimos, tendremos que seguir las vicisitudes de Martín de Álzaga para entender cómo se llegó al último juicio contra Sentenach.

\subsection{Las oposiciones a la Revolución}

Tanto los ricos comerciantes realistas, obligados a contribuir económicamente con la revolución y la guerra, como los pulperos y otros trabajadores que continuaron bajo el nuevo sistema, no vieron con buenos ojos los cambios que se habían dado en la sociedad rioplatense. Todos sufrieron paulatinamente de privaciones y acosos verbales por los criollos que, aunque había luchado con ellos en las invasiones inglesas, estaban muy crispados para con los contrarrevolucionarios. Incluso hubo intentos formales de separar a los contrarios a la Junta: a finales de 1810 se quiso excluir a los españoles de los cargos públicos y en 1811 alejar de la ciudad a los peninsulares solteros. Las dos medidas fueron combatidas por la élite de Buenos Aires, que mantenía lazos de diferente índole con los peninsulares ${ }^{105}$.

Pero el clima de violencia no sólo se debió a las oposiciones internas, fueron las fuerzas externas las que aumentaron la tensión al percibir a la Revolución como un enemigo a abatir. Entre estas fuerzas, destacamos la ya comentada oposición del virrey del Perú, José Fernando de Abascal y su brazo armado, José Manuel de Goyeneche, o los intereses de la Corte Real portuguesa, trasladada al Brasil tras la invasión napoleónica de la Península y fuertemente influenciada por Gran Bretaña. Así, el Brasil portugués pretendía convertir en su frontera más lejana el propio Río de la Plata y además contaba con las ambiciones rioplatenses de la reina consorte, Carlota Joaquina, hermana de Fernando VII que quiso heredar sus derechos soberanos sobre el territorio americano al estar este preso, como muestra en la llamada «Justa Reclamación». La presión portuguesa contra Buenos Aires se reafirmó en junio de 1811 con el envío de tropas a la Banda Oriental ante un pedido de Montevideo que tenía su campaña asediada por las fuerzas de José Gervasio de Artigas, que a su vez estaba respaldado por Buenos Aires. Es importante resaltar

\footnotetext{
102 Junta de Historia y Numismática Americana (comp.). Gaceta de Buenos Aires (1810-1821). T.I. Buenos Aires: Comp. Sud-Americana de Billetes de Banco, 1910, p.189.

103 DE ASÚA, M. La ciencia de Mayo: la cultura científica en el Río de la Plata, 1800-1820. Buenos Aires: Fondo de Cultura Económica, 2010, p. 31.

104 Junta de Historia y Numismática Americana (comp.). Gaceta de Buenos Aires (1810-1821). Op. cit., pp.190-197.

${ }_{105}$ PEREZ, M. ¡Viva España y mueran los patricios! Op. cit., p. 30.
} 
que Montevideo se había convertido, en enero de 1811, en un bastión realista tras la llegada de Elío con los poderes de nuevo virrey. Una de sus primeras iniciativas, ante la rebeldía de la Junta porteña, fue nombrar a Montevideo capital virreinal, marcando su separación total con el otro lado del río.

\subsection{Martin de Álzaga y el inicio de la conspiración}

A causa del fuerte ambiente hostil en su contra, la Junta empezó a temer una confabulación entre peninsulares contrarrevolucionarios de ambas orillas del río. Para evitarlo, a finales de agosto alejó de la ciudad a Álzaga enviándolo primero a las islas de la Magdalena y a principios de febrero de 1811 "considerándose peligrosa su presencia en aquel punto recibe orden de trasladarse a la Guardia del Salto ${ }^{106}$ », durante 8 meses. Junto a él también fueron alejados otros influyentes comerciantes (Esteban Villanueva, Juan A. Santa Coloma, Olaguer Reynals y Francisco Neyra y Arellano), muchos de los cuales habían participado en la asonada de 1809. El 20 de octubre de 1811 se firmó un armisticio entre Montevideo y Buenos Aires $^{107}$, lo cual permitió en noviembre de ese año la liberación de Álzaga y los suyos. Este marchará a su chacra en Barracas, en las afueras de Buenos Aires, dejando a su yerno Matías de la Cámara como ejecutor de sus órdenes comerciales. Para algunos autores, el intento de sublevación de 1812 tuvo una planificación previa que posiblemente se iniciara en estos exilios de 1811. Es probable también que, la persecución contra los peninsulares no adeptos a la revolución y la existencia de una fuerza exterior con capacidad para ayudarlos, fueran aliciente para preparar el golpe definitivo ${ }^{108}$. Según la historiografía revisionista no existió tal conspiración en 1812, amparándose en la inexistencia de documentos del lado ajusticiado y considerando la represión ejercida sobre los peninsulares como una simple venganza de los revolucionarios, negando el claro papel político de esos comerciantes $^{109}$.

El armisticio entre Buenos Aires y Montevideo duró poco, lo que era de esperar dada la clara incompatibilidad entre ambas posturas. Queda claro que la firma de la paz buscaba ganar tiempo para mejorar sus propias posiciones ante un último asalto. Es por eso que la escalada de violencia, lejos de menguar, fue creciendo ante las reiteradas denuncias de Buenos Aires por la ocupación portuguesa, y de Montevideo por el apoyo porteño a Artigas. A tal punto llegó la oposición que, el 6 de enero de 1812, el Gaspar de Vigodet como gobernador de Montevideo, escribió al gobierno porteño para que dejaran hacer a los portugueses contra las fuerzas de Artigas $^{110}$. En respuesta, el 13 de enero de 1812, el gobierno porteño emitió un bando por el cual:

«...todo negociante, almacenero, tendero, pulpero, consignatario, o comisionista y toda persona que por resulta de compras, o cualquier otro contrato, tuviere en su

\footnotetext{
106 WILLIAMS, E. Álzaga 1812. Buenos Aires: EMECE, 1969, p. 238.

107 Dada la extensión del artículo y la complejidad política del territorio, no podemos detallar todos los procesos de estiras y aflojas que se dieron paralelamente y entremezclados.

108 Para entender la confluencia de fuerzas opositoras y sus intereses, recomendamos revisar los primeros capítulos y el aporte documental de la obra de Álzaga 1812 de Enrique Williams Álzaga,

109 SCHLEZ, M. Los circuitos comerciales tardo-coloniales. Op. cit., p. 59.

110 Elío fue llamado por las autoridades peninsulares en noviembre de 1811.
} 
poder, o en poder de otro, aquí o en otro paraje, dineros, o especie de todo género, pertenecientes a sujetos de la España, Montevideo y territorios de la obediencia de su gobierno, o del Virreinato de Lima y pueblos subyugados por las fuerzas del ejército de Goyeneche, o residentes en dichos territorios, deberán precisamente manifestarlos a este Superior Gobierno dentro del perentorio término de cuarenta y ocho horas, y si no lo verificasen y se les descubriere alguna pertenencia no manifestada, se le confiscará irremisiblemente la mitad de sus bienes propios, e incurrirá en la pena de expatriación y privación de todos los derechos de ciudadano, patria potestad y demás que dispensa el suelo y la protección del Gobierno del país »"111.

La consecuencia inmediata del 16 de enero fue la ruptura de toda comunicación de Montevideo con Buenos Aires y el envío de José Joaquín Primo de Rivera a bloquear el puerto porteño. Mientras que algunos grandes comerciantes se plegaron ante el gobierno y mostraron todos sus números, Álzaga se negó y fue detenido. El gobierno creó una comisión para controlar estas requisas, la Comisión de Bienes Extraños, que impuso a Álzaga una fuerte multa y dispuso un aval de cinco personas para obtener su liberación. Puede que este encarcelamiento y la difícil situación externa, acelerara el plan del «Partido de la Causa Justa» ${ }^{112}$ contra los revolucionarios.

\subsection{El descubrimiento}

Parece que, al igual que en 1809, la red de espías del gobierno era muy amplia y efectiva. Gracias a ella, se recogieron diferentes rumores de pulpería, chismes y bravatas sobre la preparación de un alzamiento de peninsulares ${ }^{113}$. Esta información "de la calle» nos muestra cuán violentada estaba la población, en un ambiente en que las exageraciones de los dos bandos exacerbaron aún más los ánimos. Para los criollos la supuesta sublevación de los peninsulares pretendía «arrestar, fusilar y colgar inmediatamente todos los individuos del gobierno, los primeros magistrados, los ciudadanos americanos de crédito y patriotismo y los españoles más adictos al sistema», expulsar a todos para que «no hubiese en esta capital un solo individuo que no fuese español europeo», dando el mandato a «Martín de Álzaga, sin reconocer dependencia del gobierno de Montevideo hasta la decisión de las cortes; porque el fin era restablecer el ascendiente de los españoles, y volver a los americanos a una situación mil veces más servil que la pasada»114. Para los peninsulares los rumores iban en el sentido de que «los alcaldes tenían orden para degollar a los europeos» o «tenían un pliego del gobierno para dar libertad a los negros y matar a los Europeos» ${ }^{115}$. Es interesante la mención a los negros como parte activa de la represión contra los españoles ya que su igualación social acababa con las base tradicional de la jerarquía social colonial, invirtiendo totalmente su orden ${ }^{116}$.

\footnotetext{
111 WILLIAMS, E. Álzaga 1812. Op. cit., p. 34.

112 SCHLEZ, M. Los circuitos comerciales tardo-coloniales. Op. cit., p.140.

113 PÉREZ, M. ¡Viva España y mueran los patricios! Op. cit., p. 34.

114 BERUTI, J. M. Memorias curiosas. Biblioteca de Mayo. Colección de obras y documentos para la historia argentina. T.IV. Buenos Aires: Senado de la Nación, 1960, pp. 184-185.

115 PÉREZ, M. ¡Viva España y mueran los patricios! Op. cit., p. 35.

116 lbídem, p. 36.
} 
A esta rumorología tenemos que añadir la construcción de un lenguaje belicoso en que abundaban los insultos. Por parte de los criollos, los conocidos «godo» o "sarraceno" como marca de ser extranjero, y por parte de los peninsulares comentarios de júbilo por las victorias de los ejércitos virreinales ${ }^{117}$. Pero algo común a los dos grupos fue la certeza de la existencia de una ley diferente a la conocida en la cual aquellos que insultaban a la Revolución o amenazaban a los criollos, sobre todo en los momentos de mayor hostilidad con Montevideo, eran arrestados. De esta forma, los contrarrevolucionarios certificaban que ya no podían ampararse en el gobierno. Todo se agravaba porque las clases populares se beneficiaban de la necesidad que tenían las autoridades de contar con su apoyo político, lo que conllevaba que no podían reprimir fuertemente sus excesos ${ }^{118}$.

La denuncia que inició todo el proceso fue la de Valentina Benigna Feijoo, del 30 de junio de 1812. En ella aseguró que «un negro llamado Ventura que tiene al cuidado de un potrero de su propiedad» había sido tanteado por «un gallego» para unirse a «un levantamiento que intentan hacer los europeos, cuya cabeza de motín, (...) es don Martín Álzaga»119. Según las posteriores investigaciones, el plan de insurrección se preparaba para el 5 de julio, onomástica de la «Defensa» de 1807. Parece que el proyecto era acabar con la Revolución sublevando a algunos militares de la ciudad, previamente sobornados, junto a un refuerzo de los artilleros (sin Esteve y Llach, ya que se había jubilado en 1811) y las tropas de marinos enviadas por Montevideo.

\subsection{El juicio}

En este caso, y marcando una gran diferencia con respecto a las anteriores causas, las detenciones, el juicio y los ajusticiamientos fueron muy rápidos. Tras la denuncia inicial, el 31 de junio comenzaron los interrogatorios y sólo en la primera semana, los jueces escucharon el testimonio de más de cincuenta sospechosos. Estos sirvieron para descubrir toda una red de relaciones conspirativas que abarcaba a gran parte del abanico social peninsular: poderosos comerciantes, antiguos militares y un gran número de pulperos, marinos, pescadores y el propio Sentenach. El sistema de reclutamiento, según los testimonios, mostraba que el enganche fue de tipo personal, de paisanaje, donde una persona reclutó a los que le eran de confianza o con los que tenía relaciones laborales ${ }^{120}$. Lo irónico, siguiendo el análisis de Mariana Pérez, fue que esos vínculos no personales fueron los causantes de la caída de la conspiración. No hemos de olvidar que la Revolución de 1810, con su discurso igualitarista, rompió los mecanismos tradicionales de sometimiento y dotó de mayor libertad a las clases populares y a los esclavos. Estos, no dudaron en delatar la conspiración de los «mandones» que atentaban contra la Patria ${ }^{121}$, mostrando "las nuevas relaciones de poder y las tensiones

\footnotetext{
117 Ibídem, p. 31.

118 Ibídem, p. 32.

119 Archivo general de la República Argentina. Tomo IX-X: Periodo de la Independencia. Op. cit., p. 190.

120 PÉREZ, M. ¡Viva España y mueran los patricios! Op. cit., pp. 26-27.

121 Ibídem, p. 28. Y hacemos incidencia en la importancia del cambio de idea contra el que se atentaba.
} 
sociales que atravesaban a la sociedad porteña ${ }^{122}$ ». Si bien es cierto que al inicio de la Revolución se buscó adhesiones en todos los ámbitos, no cargando contra los grupos de oposición, en 1812, con la violencia exterior y el miedo a la contrarrevolución, se tuvo que ser muy expeditivo con los enemigos internos ${ }^{123}$.

Analizando formalmente el proceso de 1812, podemos ver cómo la justicia también había hecho el cambio revolucionario. Si en los anteriores pleitos nos habíamos encontramos ante juicios de corte «clásico» ${ }^{124}$, en 1812 todo cambió. En enero se sustituyó a la Real Audiencia por una Cámara de Apelaciones, cerrando el vínculo virreinal, y se utilizaron causas sumarias o comisiones de justicia extraordinaria ${ }^{125}$ para acelerar los procesos más urgentes (Comisión de Bienes Extraños, por ejemplo). El 22 de noviembre de 1811 el Primer Triunvirato sancionó un Estatuto Provisional que le permitía «adoptar cuantas medidas estime necesarias para la defensa y salvación de la Patria» ${ }^{126}$. Así el gobierno, que era el encargado de dictar la sentencia final contra los sublevados, designó como jueces de una comisión a Hipólito Vieytes, Bernardo Monteagudo, Pedro José Agrelo, Miguel Irigoyen y a Feliciano Antonio Chiclana (que también era vocal del triunvirato junto a Juan Martín de Pueyrredon y Bernardino Rivadavia). Su intención era llevar a cabo un rápido proceso con una sentencia ejemplar contra los infidentes a la Revolución y a la Patria. Se les juzgaba no sólo «sobre lo que han hecho, sino sobre lo que son, serán y pueden ser ${ }^{127}$ ». Y justamente por la necesidad de ser «un poder que no tiene que demostrar por qué aplica sus leyes, sino quiénes son sus enemigos» 128 llevó muchas veces el estigma de parcial aunque intentó autodotarse de reglamentos que lo avalaran ${ }^{129}$. Pese a esto la intención de la comisión estaba clara, debía:

«...sofocar de una vez para siempre, las tentativas audaces con que los españoles, vecinos de esta ciudad y provincias, meditaron concluir por sí solos la revolución y acabar con los patriotas como los negros acabaron con los blancos, en la isla de Santo Domingo; y a realizarle al gobierno ingentes sumas de dinero para las graves atenciones que lo rodeaban en las contribuciones y derechos fiscales, que eran debidos principalmente por los españoles, únicos dueños de la riqueza del país, y que se resistían a pagarlas bajo diferentes pretextos frívolos, irrespetuosos e insultantes, en hostilidad directa de la revolución» ${ }^{130}$.

Así se inició la investigación de las denuncias recibidas tras el descubrimiento de la conspiración, a las cuales se unieron las delaciones de los propios acusados. Lo curioso es que, mientras que a las delaciones se les dio un estatus de creíbles,

\footnotetext{
122 Ibídem, p. 24.

123 Ibídem, p. 30.

124 En 1810, durante el segundo juicio, el cambio fue formal. Hasta 1812 se remplazaron los funcionarios por abogados americanos de carrera y afines a la Revolución (CANDIOTI, M. Ley, justicia y revolución. Op. cit., p. 48).

${ }_{125}$ CANDIOTI, M. Ley, justicia y revolución. Op. cit., p.67.

126 Ibídem, p. 51.

127 FOUCAULT, M. Vigilar y castigar: Nacimiento de la prisión. Buenos Aires: Siglo XXI Editores, 2006, p. 27.

128 Ibídem, p. 62.

${ }^{129}$ CANDIOTI, M. Ley, justicia y revolución. Op. cit., p. 69.

130 AGRELO, J. P. Autobiografía 1810-1816. Biblioteca de Mayo. Colección de obras y documentos para la historia argentina. T.II. Buenos Aires: Senado de la Nación, 1960, p. 10.
} 
enjuiciando y castigando a los denunciados, las denuncias externas fueron sometidas a un sistema de comprobación sobre quién acusaba, a quién, las reiteraciones de acusaciones sobre el mismo personaje o las reputaciones del acusado y del denunciante ${ }^{131}$. También se revisó si tenían vínculos, personales o comerciales, para evitar intereses ocultos ${ }^{132}$. Las conversaciones, los rumores que se habían oído en una pulpería, en la calle, o el ser «presuntivamente (...) dispuesto y complotado» ${ }^{133}$ fueron miradas con reticencia por la justicia. De esta forma nos encontramos que, ante un mismo conflicto se llegaron a emitir gran variedad de sentencias. Una vez eliminados los líderes conjurados, con sentencias muy violentas, las autoridades creyeron necesario rebajar el nivel de revanchismo y frenar el anti españolismo imperante en las clases populares:

«...todo hombre se erigió en autoridad e hizo prisioneros como le dictaban las pasiones. Creí un deber ceder a las circunstancias y dejar ese desahogo (...) cuando no llegaba a la terminación de la vida de los españoles» ${ }^{134}$.

Finalmente fueron acusados 135 vecinos de ellos fueron: 29 ahorcados, 23 enviados a prisión, 11 desterrados, 43 liberados, 9 multados y de 20 no se conoce la sentencia. Varias personas más fueron detenidas sin juicio ${ }^{135}$. Dada la rapidez de la justicia y la rotundidad de las ejecuciones en forma "administrativa» podemos encontrar algunas semejanzas con la Francia del Terror. Los procesos de ejecución fueron solemnes y públicos para «reconstituir la soberanía», «manifestándola en todo su esplendor» ${ }^{136}$ ya que «por parte de la justicia que lo impone, el suplicio debe ser resonante, y debe ser comprobado por todos, en cierto modo como su triunfo' ${ }^{137}$. El 4 de julio se ahorcaron a los primeros implicados (Pedro de la Torre y Matías de la Cámara, yerno de Álzaga), mientras se buscaba a los cabecillas escondidos. El 6 de julio, tras ser detenido a las $00.30 \mathrm{~h}$, «...á las diez de la mañana fue ejecutada en la persona de Martin Álzaga la sentencia de muerte en que estaba condenado, (...) y dispuéstosele los correspondientes auxilios espirituales de que doy fe, como sé que se le mantuvo en la horca de la forma ordinaria» ${ }^{138}$. La ejecución fue por fusilamiento ${ }^{139}$ : «....no quiso que le vendaran los ojos y rogó no se le hiciera fuego al rostro, sino al pecho, diciendo á los tiradores: Muchachos, cumplan ahora con su deber». Finalmente su cuerpo se dejó expuesto y «aun en la horca lo apedrearon, y le proferían a su cadáver mil insultos, en términos que parecía un judas de sábado santo» ${ }^{140}$.

\footnotetext{
${ }^{131}$ Francisco de Tellechea fue denunciado por su capataz y aunque se sabía de su odio contra él, las múltiples denuncias de otros, provocaron la muerte del comerciante (PÉREZ, M. ¡Viva España y mueran los patricios! Op. cit., p. 34-nota 35).

132 Algunos acusados pudieron salvarse por el testimonio de algún conocido adepto a la Revolución.

133 PÉREZ, M. ¡Viva España y mueran los patricios! Op. cit., p. 43.

134 Visto en SCHLEZ, M. Un antagonismo larvado. Conflictividad y reyertas entre los comerciantes rioplatenses (1789-1794). História, histórias. 2014, vol. 2, n. 3, p. 142, original AGN, Sala X, 6-7-11.

135 PÉREZ, M. ¡Viva España y mueran los patricios! Op. cit., p. 34-nota 36.

${ }^{136}$ FOUCAULT, M. Vigilar y castigar. Op. cit., p. 54.

137 Ibídem, p. 40.

138 Archivo general de la República Argentina. Tomo IX-X: Periodo de la Independencia. Op. cit., pp. 83-84.

139 WILLIAMS, E. Álzaga 1812. Op. cit., p. 277.

140 BERUTI, J. M. Memorias curiosas. Op. cit., p.184.
} 
Pese a la brutalidad contra Álzaga, al igual que se hizo con Liniers en 1810, el objetivo final nunca fue causar dolor físico a los culpables. La diferencia entre los dos fue que mientras la muerte de Liniers no podía ser mostrada al pueblo por el gran aprecio que le tenían las clases populares, la muerte de Álzaga fue de gran regocijo para estas por lo que representaba ${ }^{141}$. Se le conocía como opositor al sistema revolucionario, gran comerciante y conservador, pero también se olvidó que solo seis años antes fue aclamado como héroe de la «Defensa». Tras su ejecución el público gritó «Viva la patria» y «muera el tirano» repetidas veces con un fondo de canciones patrióticas tocadas por una banda militar ${ }^{142}$. Además, se celebró un Tedeum en la Catedral por la victoria frente a la conspiración y hubo tres noches de iluminación general e incluso varios individuos tiraron públicamente dinero ${ }^{143}$.

\section{A Sentenach se le acusó porque:}

«...prostituyendo las sagradas obligaciones y reconocimiento en que se veía constituido para con la Patria y sus hijos no trepidó en admitir tratado ó propuesta para ella, con el Jefe y principal conjurado Martín Álzaga, según en parte lo tiene confesado él mismo bajo la sola increíble, y general excusa de todo delincuente de no haberla aceptado, cuando de el solo hecho de ser provocado, é invitado para el efecto, y no denunciarlo le convence un formal crimen en este orden, y una positiva disposición, á tomar en su caso el partido que se le daba, ó proponía principalmente en las circunstancias de ser uno de los europeos, que más consideraciones había merecido del Gobierno, y doblemente obligado á sacrificar su fidelidad en obsequio de las provincias y sus pacíficos naturales; para castigar su delito de un modo condigno y proporcionado á la generosidad con que se le ha tratado» ${ }^{144}$.

Fue declarado culpable y el 11 de julio, para su ajusticiamiento:

«...se construyó un tablado (...) para degradar á los militares. Subíase a él por una escalinata de madera que miraba al arco de triunfo de la Recova, bajándose por otra hacia el banquillo. Así murió el ingeniero español Felipe Sentenach, teniente coronel de artillería, profesor de matemáticas y uno de los corifeos de la conjuración. Su espada fue previamente inutilizada por mano del verdugo, después de haber sido despojado del hábito militar con las formalidades de ordenanza»145.

Tras su degradación, fue fusilado en la Plaza Mayor, que en aquel entonces se llamaba de la Victoria, y su cadáver colgado ${ }^{146}$.

\footnotetext{
141 FOUCAULT, M. Vigilar y castigar. Op. cit., p. 62.

142 BERUTI, J. M. Memorias curiosas. Op. cit., p. 184.

143 Ibídem.

144 Archivo general de la República Argentina. Tomo IX-X: Periodo de la Independencia. Op. cit., p. 114.

145 Testimonio de Santos Fortunato Vallester en WILLIAMS, E. Álzaga 1812. Op. cit., p. 284.

${ }^{146}$ Como curiosidad, existe la relación de objetos que tenía Sentenach en su cuarto, revisado tras su muerte. Cuenta con la biblioteca personal y los títulos de las obras. AGN, Sala IX, caja 15-02-12, División colonia, Sección Gobierno, Pertenencias extrañas, varios años.
} 
El 13 de julio fue excomulgado, ajusticiado y su cuerpo expuesto ${ }^{147}$ otro de los cabecillas, el fraile betlemita José de las Ánimas, ex-capitán del ejército español en la guerra contra la Convención (1793-95).

Este ejercicio de los ajusticiamientos «está destinado (...) a volver infame a aquel que es su víctima; el propio suplicio, si bien tiene por función la de "purgar" el delito, no reconcilia» 148 con la idea de intimidar a los adeptos que quedaran del partido de Álzaga, y de paso abrir una espita para la furia de la ciudadanía ${ }^{149}$. Pese a ello, el 24 de julio finalizaron las ejecuciones, instando las autoridades al pueblo a reconciliarse con los españoles que defendían la causa americana. Esto contrarió a unas clases populares radicalizadas contra los españoles, que llegaron a insultar en su domicilio a los triunviros ${ }^{150}$ e hicieron huir a algunos peninsulares favorables a la revolución ${ }^{151}$.

\subsection{Consecuencias}

Una vez neutralizado el miedo contrarrevolucionario interno, las fuerzas al mando se pudieron volcar hacia la oposición exterior, pero eso no evitó que se siguiera con una política intolerante contra los peninsulares: se les requisaron todas las armas blancas y de chispa ${ }^{152}$, se les prohibió tener pulperías y se ordenó a los artesanos que empleasen en sus talleres, como mozos o ayudantes a americanos. Esto rompía con la tradición de afiliación de peninsulares por paisanaje ${ }^{153}$ y modificaba los engranajes que permitían a los peninsulares aislar a los americanos de trabajos de gran influencia e importancia para las clases populares. También fueron eliminados los peninsulares «del comercio al menudeo", pero rápidamente se comprobó que los afectados fueron los de nivel medio y pequeño, ya que no se hicieron grandes disposiciones contra los comerciantes ricos. Por ejemplo, se intentó respetar la fortuna de los hijos criollos de Álzaga, ya que «a la élite criolla no le interesa tutelar los intereses de los peninsulares como grupo, pero sí salvar a sus respectivos protegidos». Otro ejemplo de esta violencia contra los peninsulares fueron las cartas de ciudadanía, herramienta que diferenció legalmente a los favorables a la revolución de los contrarios porque sólo con ellas se podía comerciar y ejercer empleos públicos ${ }^{154}$. Cabe decir que su concesión muy pronto se convirtió en un arma en manos criollas para resolver rencillas personales e incluso contra

\footnotetext{
147 Archivo general de la República Argentina. Tomo IX-X: Periodo de la Independencia. Op. cit., p. 153.

148 FOUCAULT, M. Vigilar y castigar. Op. cit., p. 40.

149 lbídem, p. 99.

150 Algunos «tumultuarios» fueron aprisionados y enviados al Ejército del Norte o presos en la campaña (DI MEGLIO, G. (2006). "Os habéis hecho temibles». Op. cit., p. 151.).

151 Es el caso de Juan Manuel Fernández de Agüero (SCHLEZ, M. Los circuitos comerciales tardocoloniales. Op. cit., p. 142.).

152 SCHLEZ, Mariano. Un antagonismo larvado. Conflictividad y reyertas entre los comerciantes rioplatenses (1789-1794). História, histórias. Revista do Programa de Pós-graduação em História da UnB. 2014, vol. 2, n. 3, p. 68.

153 PÉREZ, M. ¡Viva España y mueran los patricios! Op. cit., p. 47 y DI MEGLIO, Viva el...op.cit., p.150.

154 HALPERIN, T. Revolución y guerra: formación de una elite dirigente en la Argentina criolla. Buenos Aires: Siglo XXI Editores Argentina, 2005, p. 184.
} 
españoles favorables a la Revolución ${ }^{155}$.

Aunque en la memoria colectiva el fin de la conspiración se asoció al fin de la influencia española en el territorio, dentro de la élite rioplatense se mantuvo la presencia e influencias de los clanes familiares revolucionados, ya que estaban fuertemente ligados por matrimonios, negocios e intereses entre ellos. Pero el mito se mantuvo porque tanto el triunvirato como sus gobiernos posteriores, no quisieron romper la idea porque necesitaban enaltecer la victoria criolla. Podemos analizar este silencio bajo el prisma de que «todo poder se rodea de representaciones, símbolos, emblemas, etc., que lo legitiman, lo engrandecen, y que necesita para asegurar su protección» ${ }^{156}$. Así, el verdadero problema de la élite porteña fue compaginar la necesidad de mantener contentas a las clases populares con la defensa de las solidaridades familiares y de clase que incluían a los peninsulares ${ }^{157}$. Esto se hizo desligando a los contrarrevolucionarios de sus «familias inocentes» y enaltecer a aquellos españoles «sensatos y beneméritos» ${ }^{158}$ que apoyaban la Revolución.

\section{Conclusión}

Para poder entender las sociedades en conflicto, sobre todo las que se encuentran en un cambio de paradigma, es importante no obviar ningún aspecto que nos dé pistas acerca de cuáles fueron las problemáticas que vivieron, qué grupos las apoyaron/repudiaron y de qué estrategias se valieron para encararlas. En nuestro caso hemos podido comprobar cómo, en un contexto determinado y en un territorio definido, el estudio de tres procesos judiciales contra un mismo personaje puede mostrar qué fue lo que verdaderamente se puso en juego. Hemos visto cómo, a pesar de la paulatina imposición de la idea de separación de poderes, en las primeras décadas del siglo XIX la justicia todavía era un territorio en donde la situación política devino en un elemento clave. Es por eso que, sin querer restarle importancia al propio hecho judicial, hemos analizado de qué manera los vínculos con el poder, tanto de la sociedad tardo-colonial como postrevolucionaria, son la clave para entender cómo Felipe de Sentenach, en menos de seis años, fue acusado dos veces de «infidente a la monarquía» y una tercera, por traidor a la Patria. Sin ello no se comprendería cómo los engranajes de relaciones e intereses salvaron dos veces de una muerte segura, a los acusadores con falso testimonio y en la tercera, las sentencias fatales fueron dictadas en menos de una semana.

Por ello hemos creído conveniente remarcar las ambiciones personales, las formas de entender la sociedad virreinal y los conflictos imperiales como medio para comprender el alto grado de conflictividad y, en definitiva, el cambio de percepción sobre qué sistema necesitaba la sociedad rioplatense. Incluso creemos haber demostrado cómo los juicios de 1807 y 1809 estuvieron unidos por una línea que respondía a la fricción entre «facciones» más o menos equiparables, mientras que el de 1812 respondió a una lucha agresiva y a un coup de force que sólo podía acabar

\footnotetext{
155 SCHLEZ, M. Los circuitos comerciales tardo-coloniales. Op. cit., p. 142.

${ }^{156}$ BACZKO B. Los imaginarios sociales. Op. cit., p. 8.

157 BERUTI, J. M. Memorias curiosas. Op. cit., p. 185.

158 PÉREZ, M. ¡Viva España y mueran los patricios! Op. cit., p. 58.
} 
con la eliminación de uno de los dos opositores.

Profundizar en estos conflictos «particulares», que en verdad son generales, permite enriquecer con nuevas aproximaciones las visiones sobre el fin del Imperio y el advenimiento de la «gloriosa revolución», piedra fundacional de la construcción histórica de Argentina. Con ello podemos comprender la gran complejidad del proceso, más allá de los mitos y la diversidad de posicionamientos y los espacios grises que los acompañaron. Así cobra más significado la presencia en los tres juicios, de una forma u otra, de la mayoría de los personajes implicados directamente en los momentos históricos de cambio.

En definitiva, hemos mostrado cómo el uso de una fuente que muchas veces ha sido utilizada sólo en forma textual, nos ha permitido conocer mejor las relaciones sociopolíticas y de intereses que se pusieron en juego una vez iniciados los litigios. Serán estos vínculos, y no otros, los que de una forma directa o indirecta, sean verdaderamente juez y parte para los encausados y sus destinos en el proceso revolucionario.

\section{Documentación y Bibliografía}

\subsection{Archivos}

AGl: Archivo General de Indias, Sevilla.

AGN: Archivo General de la Nación, Buenos Aires.

ARACAB: Reial Acadèmia de Ciències i Arts de Barcelona, Barcelona.

RAE: Real Academia Española (de la lengua)

\subsection{Recopilaciones}

Archivo general de la República Argentina. Tomo IX-X: Periodo de la Independencia, causa de Álzaga 1812. Buenos Aires: Kraft, 1897.

Biblioteca de Mayo. T.XI: Sumarios y expedientes: Documentos relativos a los sucesos ocurridos en Buenos Aires el $1^{\circ}$ de enero de 1809. Buenos Aires: Senado de la Nación, 1961.

Biblioteca de Mayo. T.XII. Sumarios y expedientes: Proceso contra Martin de Álzaga, Felipe de Sentenach y José Miguel de Ezquiaga. Buenos Aires: Senado de la Nación, 1961.

Junta de Historia y Numismática Americana (comp.). Gaceta de Buenos Aires (18101821). T.I. Buenos Aires: Comp. Sud-Americana de Billetes de Banco, 1910.

MALLIE, A. (comp.). Acuerdos del extinguido cabildo de Buenos Aires, Serie IV, T.II T.III. Buenos Aires: Senado de la Nación, 1926. 
MALLIE, A. Acuerdos del extinguido cabildo de Buenos Aires, Serie IV, T.IV. Buenos Aires: Senado de la Nación, 1927.

MALLIE, A. La Revolución de Mayo a través de los impresos de la época. T.I (18091811) y T.II (1812-1815). Buenos Aires: Comisión Nacional Ejecutiva del $150^{\circ}$ Aniversario de la Revolución de Mayo, 1965.

\subsection{Bibliografía y artículos}

AGRELO, J. P. Autobiografía 1810-1816. Biblioteca de Mayo. Colección de obras y documentos para la historia argentina. T.II. Buenos Aires: Senado de la Nación, 1960, pp.1293(1) - 1324(32) $)^{159}$.

ÁLZAGA, Enrique. Álzaga, 1812. Buenos Aires: Emecé Editores, 1968.

ÁLZAGA, Enrique. Documentos relativos a la actuación de Martín de Álzaga en la Reconquista y en la Defensa de Buenos Aires (1806-1807). Buenos Aires, 1948.

ÁLZAGA, Enrique. Dos revoluciones. 1ํ de Enero 1809-25 de Mayo 1810. Buenos Aires: Emecé, 1963.

ÁLZAGA, Enrique. Fuga del General Beresford, 1807. Buenos Aires: Emecé Editores, 1965.

ÁLZAGA, Enrique. Martín de Álzaga en la reconquista y en la defensa de Buenos Aires 1806-1807. Buenos Aires: Emecé Editores, 1971.

ÁLZAGA, Enrique. Martín de Álzaga. Cartas (1806-1807). Buenos Aires: Emecé Editores, 1972.

ÁLZAGA, Enrique. Vida de Martín de Álzaga. Buenos Aires: Emecé Editores, 1984.

ANÓNIMO. Diario de un soldado. Buenos Aires: Ministerio del Interior, 1960.

ÁVILA, Alfredo y PÉREZ, Pedro (coords.). Las experiencias de 1808 en Iberoamérica. México: UNAM; Alcalá de Henares: UAH, 2008.

BACZKO B. Los imaginarios sociales. Memorias y esperanzas colectivas. Buenos Aires: Nueva Visión, 1999.

BERUTI, J. M. Memorias curiosas. Biblioteca de Mayo. Colección de obras y documentos para la historia argentina. T.IV. Buenos Aires: Senado de la Nación, 1960, pp. 3646(1) - 4150(504).

BEVERINA, J. El Virreinato de las Provincias del Río de la Plata. Su organización militar. Buenos Aires: Círculo Militar; Biblioteca del Oficial, 1992.

${ }^{159}$ Las obras de esta colección contienen una doble paginación, de ahí la decisión de marcar las dos para facilitar las opciones de búsqueda. 
BREÑA, Roberto (coord.). Iberoamérica en 1810: Emancipación, autonomía y lealtad. Historia y Política. 2010, n. 24.

CANDIOTI, M. Ley, justicia y revolución. La justicia en la ciudad de Buenos Aires. 1810-1821. Las Tesis del Ravignani [en línea]. .2015, n. 4. [Consulta: 15-07-17]. Disponible en <http://www.ravignanidigital.com.ar/tms/series/tesis_ravig/ttr-004tesis-candioti-2010.pdf>.

CHUST, Manuel (coord.). 1808. La eclosión juntera en el mundo hispano. México: FCE; Colmex, 2007.

DE ASÚA, M. La ciencia de Mayo: la cultura científica en el Río de la Plata, 18001820. Buenos Aires: Fondo de Cultura Económica, 2010.

DI MEGLIO, G. (2006). «Os habéis hecho temibles». La milicia de la ciudad de Buenos Aires y la política entre las invasiones inglesas y el fin del proceso revolucionario, 1806-1820. Tiempos de América: revista de historia, cultura y territorio [en línea]. 2006, n. 13, pp. 151-166. [Consulta: 07/06/17], Disponible en $<$ http://www.raco.cat/index.php/TiemposAmerica/article/view/105689/163950>.

DI MEGLIO, G. ¡Viva el bajo pueblo! La plebe urbana de Buenos Aires y la política entre la revolución de mayo y el rosismo. Buenos Aires: Prometeo, 2006.

FOUCAULT, M. Vigilar y castigar: Nacimiento de la prisión. Buenos Aires: Siglo XXI Editores, 2006.

GALMARINI, H. La situación de los comerciantes españoles en Buenos Aires después de la revolución de mayo 1810. Revista de Indias. 1984, n. 173, pp. 273-290.

GUERRA, F.X. Modernidad e independencias. Ensayos sobre las revoluciones hispánicas. Madrid: Encuentro, 2009.

HALPERIN, T. Revolución y guerra: formación de una elite dirigente en la Argentina criolla. Buenos Aires: Siglo XXI Editores Argentina, 2005.

HALPERIN, T. Revolutionary militarization in Buenos Aires 1806-1815. Past and Present. 1968, n. 40, pp. 84-107.

HARARI, F. ¿Ampliación política o crisis orgánica?: un análisis del Cuerpo de Patricios, 1806-1810. Anuario del Instituto de Historia Argentina [en línea]. 2006, n. 6, pp. 1-21. [Consulta: 27-07-2017]. Disponible en $<$ http://www.fuentesmemoria.fahce.unlp.edu.ar/art revistas/pr.58/pr.58.pdf>.

LESSER, R. Los orígenes de la Argentina: historias del Reino del Río de la Plata. Buenos Aires: Biblos, 2003. 
LOZIER, B. Martín de Álzaga; historia de una trágica ambición. Buenos Aires: Editorial Ciudad Argentina, 1998.

MARTí, P. Historia de la artillería argentina. Buenos Aires: Comisión del Arma de Artillería "Santa Bárbara", 1982.

MARTÍNEZ, D. Aproximación a los voluntarios catalanes en la Defensa y Reconquista de Buenos Aires (1806-1807). En: DALLA-CORTE, G.; PIQUERAS, R. y TOUS, M. (coords.). Construcción social y cultural del poder en las Américas [en línea]. Barcelona: Fundació Casa Amèrica Catalunya, 2015, pp. 88-103. [Consulta: 04-05-2017]. Disponible en <http://www.americat.cat/es/construccionsocial-y-cultural-del-poder-en-las-americas es>.

MARTÍNEZ, D. La comunidad catalana y la revolución de Mayo: algo más que comerciantes. En: DALLA-CORTE, G.; GARZA, G. y PIQUERAS, R. (coords.). Iberoamérica, España, Catalunya. Intercambios desde la Geografía y la Historia [en línea]. Barcelona: Edición Km 13.774; Fundació Casa Amèrica Catalunya, 2016, pp. 45-64. [Consulta: 02-07-2017]. Disponible en $<$ http://americat.barcelona/uploads/20161124/lberoamerica Espan a Catalun a 2016.pdf>.

MARTÍNEZ, D. Los ingleses no son el único enemigo. Las luchas internas en el virreinato del Río de la Plata a través de dos juicios, EN: DALLA-CORTE, G.; GARZA, G.; PIQUERAS, R. y ZAIDENWERG, C. (coords). Ciencias sociales, humanidades y derecho: Cómo pensar el mundo latinoamericano [en línea]. Barcelona: Universidad de Barcelona; Mendoza: Universidad Nacional de Cuyo, 2017, pp. 85-92. [Consulta: 07-06-17]. Disponible en: $<$ https://dialnet.unirioja.es/servlet/libro?codigo=698016 $>$.

MATHEU, D. Autobiografía. Biblioteca de Mayo. Colección de obras y documentos para la historia argentina. T.III. Buenos Aires: Senado de la Nación, 1960, pp. 2217(1)-3102(886).

PÉREZ, M. ¡Viva España y mueran los patricios! La conspiración de Álzaga de 1812. Americanía. Revista de Estudios Latinoamericanos. Nueva Época. 2015, n. especial, pp. 21-55.

POLASTRELLI, I. Faltando a los deberes de buen vasallo. El juicio a los acusados de intentar independizar el Río de la Plata, 1809-1810. En: POLIMENE, María Paula (coord). Autoridades y prácticas judiciales en el Antiguo Régimen. Problemas jurisdiccionales en el Río de la Plata, Córdoba, Tucumán, Cuyo y Chile. Rosario: Prohistoria ediciones, 2011, pp. 201-220.

POLASTRELLI, I. La disidencia política y sus condenas. Los juicios a Martín de Álzaga, 1809-1812. En: TEJERINA, Marcela (comp.). Definir el otro. El Río de la Plata en tiempos de cambio (1776-1820). Bahía Blanca: EDIUNS, 2012, pp. 109137. 
PORTILLO, José María (coord.). 1808, Crisis y soberanía. Historia y Política. 2008, n. 19.

RABINOVICH, Alejandro. La société guerrière. Pratiques, discours et valeurs militaires dans le Rio de la Plata (1806-1852). Rennes: Presses universitaires, 2013.

REGUERA, A. De las biografías a los estudios de caso. La construcción de la diferenciación social. En: BONAUDO, Marta; REGUERA, Andrea y ZEBERIO, Blanca (coords.). Las escalas de la historia comparada. Tomo I: Dinámicas sociales, poderes políticos y sistemas jurídicos. Buenos Aires: Miño y Dávila Editores, 2008, pp. 49-66.

SAAVEDRA, C. Memoria Autógrafa, Biblioteca de Mayo. Colección de obras y documentos para la historia argentina. T.II. Buenos Aires: Senado de la Nación, 1960, pp. 1027(1)-1138(111).

SÁBATO, H. "Cada lector es un brazo armado». Apuntes para una historia de las milicias. En: BONAUDO, Marta; REGUERA, Andrea y ZEBERIO, Blanca (coords.). Las escalas de la historia comparada. Tomo I: Dinámicas sociales, poderes políticos y sistemas jurídicos. Buenos Aires: Miño y Dávila Editores, 2008, pp. 105-125.

SALAS, A. Crónica y diario de Buenos Aires: 1806 Y 1807. Buenos Aires: Biblioteca Nacional, 2013. 2 vols.

SCHLEZ, M. Los circuitos comerciales tardo-coloniales. El caso de un comerciante monopolista: Diego de Agüero (1770-1820) [tesis doctoral]. Buenos Aires: Universidad de Buenos Aires, 2014.

SCHLEZ, M. Un antagonismo larvado. Conflictividad y reyertas entre los comerciantes rioplatenses (1789-1794). História, histórias. 2014, vol. 2, n. 3, pp. $55-71$.

TERNAVASIO, Marcela, Gobernar la revolución. Poderes en disputa en el Río de la Plata, 1810-1816. Buenos Aires: Siglo XXI, 2007.

TJARKS, G. O., El consulado de Buenos Aires y sus proyecciones en la historia del Río de la Plata. Vol. I. Buenos Aires: Universidad de Buenos Aires, 1962.

VAZQUEZ, H. Santiago de Liniers. Madrid: Encuentro, 2012.

WILLIAMS, E. Álzaga 1812. Buenos Aires: EMECE, 1969.

WILLIAMS, E. Fuga del general Beresford, 1807. Buenos Aires: EMECE, 1965. 